\title{
SARNET benchmark on Phébus FPT3 integral experiment on core degradation and fission product behaviour
}

M. Di Giuli ${ }^{\mathrm{a}, 1}$, T. Haste ${ }^{\mathrm{a} *}$, R. Biehler ${ }^{\mathrm{a}, 2}$, L. Bosland ${ }^{\mathrm{a}}$, L. E. Herranz ${ }^{\mathrm{b}}$, J. Fontanet ${ }^{\mathrm{b}}$, E. Beuzet $^{\mathrm{c}}$,

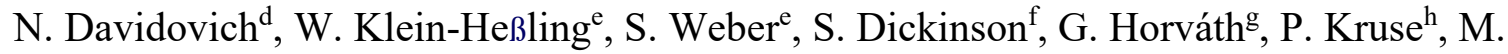

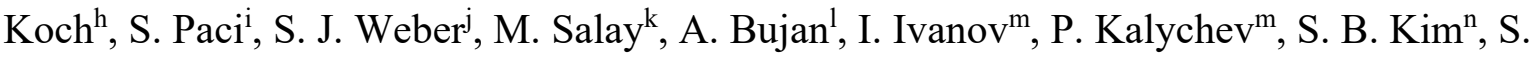

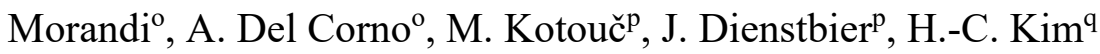

\author{
${ }^{a}$ IRSN, Cadarache, France \\ ${ }^{\mathrm{b}}$ CIEMAT, Madrid, Spain \\ ${ }^{\mathrm{c}}$ EDF, Clamart, France \\ ${ }^{\mathrm{d}}$ ENEA, Bologna, Italy
}

${ }^{\mathrm{e}} \mathrm{GRS}$, Garching and Cologne, Germany

${ }^{\mathrm{N} N N L}$, Didcot, UK

gNUBIKI, Budapest, Hungary

${ }^{\text {h} R U B, ~ U n i v . ~ B o c h u m ~, G e r m a n y ~}$

${ }^{i} U N I P I$, Univ. Pisa, Italy

${ }^{\mathrm{j} S N L}$, Albuquerque, USA

${ }^{\mathrm{k}}$ USNRC, Washington D.C., USA

${ }^{1}$ VUJE, Trnava, Slovakia

mTUS, Univ. Sofia, Bulgaria

${ }^{n}$ KAERI, Taejon, Republic of Korea

${ }^{\circ} \mathrm{RSE}$, Milan, Italy

pUJV, Rez, Czech Republic

${ }^{\mathrm{q}} \mathrm{KINS}$, Taejon, Republic of Korea

*Corresponding author: Tim HASTE ; Institut de Radioprotection et de Sûreté Nucléaire (IRSN), PSNRES/SAG/LETR - Bât 702, BP 3, F-13115 St-Paul-Lez-Durance Cedex, France, Tel:(+33) 4-42-19-95-67 / Fax: (+33) 4-42-19-91-67, Email: tim.haste@irsn.fr

${ }^{1}$ Att. From ENEA, Bologna; ${ }^{2}$ Present address: CS-SI, Aix-en-Provence, France 


\begin{abstract}
In the European $7^{\text {th }}$ Framework SARNET project, European Commission (EC) co-funded from 2008 to 2013, work package WP8.3 "Bringing Research Results into Reactor Application”, task "Benchmarking of available codes against integral experiments" the Phébus FPT3 experiment was chosen as the basis for such a benchmark. The aim of the benchmark was to assess the capability of computer codes to model in an integral way the physical processes taking place during a severe accident in a pressurised water reactor, from the initial stages of core degradation, fission product, actinide and structural material release, their transport through the primary circuit and the behaviour of the released fission products in the containment.

The FPT3 Benchmark was well supported, with participation from 16 organisations in 11 countries, using 8 different codes. The temperature history of the fuel bundle and the total hydrogen production, also taking into account of the hydrogen generated by the boron carbide control rod oxidation were well captured, but no code was able to reproduce accurately the final bundle state, using as bulk fuel relocation temperature, the temperature of the first significant material relocation observed during the experiment. Total volatile fission product release was well simulated, but the kinetics were generally overestimated. Concerning the modelling of semi-volatile, low-volatile and structural material release, the models need improvement, notably for Mo and Ru for which a substantial difference between bundle and fuel release was observed, owing to retention in the upper part of the bundle. The retention in the circuit was not well predicted, this was due mainly to the boron blockage formation in the rising line of the steam generator, and the volatility of some elements (Te, Cs, I) could be better predicted.

Containment thermal hydraulics were are well calculated, while as regards the containment aerosol depletion rate, only the stand-alone cases (in which the input data were derived from experimental data) provided acceptable results, whilst the integral cases (in which the input data
\end{abstract}


came from circuit calculations) tended to largely overestimate the total aerosol airborne mass, due to the propagation of the errors from the previous phases.

Calculation of iodine chemistry in the containment turned out to be a major challenge. Its quality strongly depends on the correct prediction of chemistry speciation in the integral codes. The major difficulties are related to the presence of high fraction of iodine in gaseous form in the primary circuit during the test, which is not correctly reproduced by the codes. This inability of the codes compromised simulation of the observed iodine behaviour in the containment.

In the benchmark a significant user effect was detected (different results being obtained by different users of the same code) which had to be taken into account in analysing the results. This article reports the benchmark results comparing the main parameters, and summarises the results achieved and the implications for plant calculations which follow. Relevant experimental and theoretical work is under way to resolve the issues raised.

\section{Keywords}

Phébus FPT3; severe accidents; code simulation; benchmark;

\section{Research highlights}

- Phébus tests studied bundle degradation and release, transport and deposition of fission products.

- Bundle temperatures and total high volatile fission product release are well predicted.

- Kinetic models for fission product and structural material release need improvement.

- No code predicts that iodine was mainly gaseous in the containment atmosphere.

- The "user effect" on the quality of the results was large. 


\section{INTRODUCTION}

Following the 1979 accident at the Three Mile Island Nuclear Plant, Unit 2 (TMI-2) (Broughton et al., 1989), it was recognized that severe accidents needed further attention, and a worldwide effort has been undertaken to understand more fully severe accident phenomena in nuclear reactors. Development and assessment of the computer codes used for severe accident analysis has taken place on international basis using a wide range of integral and separate-effects experiments. Among the integral experiments, the international Phébus FP experimental programme has been the most important nuclear safety project in the world. This programme allowed core meltdown accidents in Light Water Reactor (LWR) ${ }^{1}$ to be reproduced in representative conditions on a reduced scale. It was initiated in 1988 by the French Institut de Radioprotection et de Sûrete Nucléaire (IRSN) and the Joint Research Centre (JRC) of the European Commission (EC) (von der Hardt et al., 1994). The aim of this program was to study the degradation phenomena and the behaviour of fission products (FPs)

\footnotetext{
${ }^{1}$ Abbreviations : AIM, Advanced Iodine Model; ASTEC, Accident Source Term Evaluation Code; ATHLET-CD, Analysis of THermal-hydraulics of LEaks and Transients - Core Degradation; BIP, Behaviour of Iodine Project; CEA, Commissariat à l'Énergie Atomique et aux Énergies Alternatives, France; CHIP, Experimental programme for Chemistry of Iodine in the Primary Circuit; CIEMAT, Centro de Investigaciones Energeticas Medio Ambientales y Tecnologica; CSNI, Committee on Safety of Nuclear Installations; EC, European Commission; EdF, Electricité de France; EPICUR, Experimental Programme for Iodine Chemistry Under Radiation; ENEA, Agenzia nationale per le nuove tecnologie, l'energia e lo sviluppo economico sostenibile, Italy; ENSI, Eidgenössischen Nuklearsicherheitsinspektorats, Swiss nuclear regulator; EU, European Union; FP, Fission Product; FPT, Phébus Fission Products Test; Gesellschaft für Anlagen- und Reaktorsicherheit (GRS) gGmbH; HSK, Hauptabteilung Sicherheit Kernenergie, former name of Swiss Nuclear Inspectorate; i.i., initial inventory; IODE, ASTEC module for iodine and ruthenium behaviour in-containment; IOx, iodine oxide; IRSN, Institut de Radioprotection et de Sûreté Nucléaire; ISTP, International Source Term Program; ISP, International Standard Problem; ISTP, International Source Term Project; JAEA, Japanese Atomic Energy Agency, JNES, Japanese Nuclear Energy Society; KAERI, Korean Atomic Energy Research Institute; KINS, Korean Institute for Nuclear Safety; LWR, Light Water Reactor; MAAP, Modular Accident Analysis Program; MELCOR, Methods for Estimation of Leakages and Consequences of Releases; MIRE, Mitigation des Rejets à l'Environnement; NNL, National Nuclear Laboratories; NUBIKI, Nuclear Safety Research Institute, Ltd., Nukleáris Biztonsági Kutatóintézet Kft, Hungary; NPP, Nuclear Power Plant; NUGENIA, NUclear GEN II \& III Association; OECD, Organisation for Economic Cooperation and Development; Phébus FP, Programme to improve the understanding of the phenomena occurring during a core meltdown accident in a light water reactor; PSI, Paul Scherrer Institut; PWR, Pressurised Water Reactor; RI, organic iodide; RSE, Ricerca Sistema Energetico, Italy; RCS, Reactor Coolant System; RUB, Ruhr-University Bochum, Germany; SA, Severe Accident; SARNET, Severe Accident Research Network; SS, Stainless Steel; STEM, Experimental programme for study of Source Term and Mitigation; ST, Source Term; THAI, Experimental programme for Thermal Hydraulics And Iodine; TUS, Technical University of Sofia, Bulgaria; UJV, Ústav jaderného výzkumu Řež, Czech nuclear research institute; UNIPI, University of Pisa, Italy; USNRC, United States Nuclear Regulatory Commission; VTT, Technical Research Centre of Finland, Teknologian tutkimuskeskus VTT; VUJE, Výskumný ústav jadrových elektrární, Slovakian Nuclear Power Plant Research Institute.
} 
released in the reactor coolant system and the containment. The program matrix consisted of five in-reactor tests, performed under different conditions (March and Simondi-Teisseire, 2013).

In the frame of the SARNET2 (Van Dorsselaere et al., 2015) work package WP8.3, the last test of the series, namely Phébus FPT3, was chosen as comparative exercise. For the FPT3 test, predictions or recalculations of the main physical parameters with different computer codes were compared with each other and above all with the experimental data, to promote the international exchange of experience among the participants in the use of nuclear safety codes. The main objectives of the FPT3 benchmark were to assess the capability of computer codes to reproduce in an integral way the physical processes taking place during a severe accident in a PWR, notably as regards the treatment of strongly coupled processes, (i.e. fuel degradation with associated hydrogen production and fission product release, fission product and structural material transport in the primary circuit, aerosol behaviour in the containment and iodine radiochemistry), as identified in the OECD/CSNI International Standard Problem 46 based in Phébus FPT1 (Clément et al., 2005). The organisation of the present benchmark largely follows that of ISP-46.

The FPT3 benchmark has resulted in increased confidence in the validity and accuracy of analytical tools, which are needed to assess the safety of nuclear installations, and improve the ability of the organisation involved. The experiment was conducted as an open exercise, with all the relevant experimental data being available to the participants. The four areas covered by the experiment and therefore by the FPT3 benchmark, are the following (Clement and Zeyen, 2013):

- Fuel degradation, hydrogen and carbonaceous gas generation, release of fission products, actinides, and structural materials ('bundle' phase 1); 
- Fission product, actinide and structural material transport in the circuit, in aerosol and gaseous forms ('circuit' phase 2);

- Thermal hydraulics and aerosol physics in the containment ('containment' phase 3);

- Iodine chemistry in the containment ('chemistry' phase 4).

The emphasis was on integral calculation (all phases) and on the use of the codes as in plant studies i.e. with standard models/options as far as possible, representing the facility in a similar level of detail.

\section{SCHEDULE AND PARTICIPATION}

The benchmark started in February 2011, with a time scale of 2.5 years. A key event was the finalisation of the Phebus FPT3 Final Report (Payot et al, 2011) in July 2011, thus making the detailed results in final form to all the benchmark participants. The issue of a draft version of the Specification Report in advance of the first meeting in March 2011 allowed time for comments, which were taken into account in the final version. The most intensive phases were preparation of the specification (6 months), participants' calculations and submission of their results ( 1 year), and the coordinators analysis of the results and draft of the Comparison Report (7 months). Submissions were received from 16 organisations in 11 countries. The latter comprised Bulgaria, Czech Republic, France, Germany, Hungary, Italy, Korea, Slovakia, Spain, UK and USA. The participating organisation included utilities, regulators and their technical support organisations and research institutes, thus providing a good range of backgrounds to the technical work.

Eight different codes were used: ASTEC (van Dorsselaere et al, 2009), ATHLET-CD (Trambauer et al., 2011), COCOSYS/AIM (Allelein et al., 2008; Weber and Funke, 2009), 
ECART (Parozzi, 2006), INSPECT/IODAIR (Dickinson and Sims, 2000), MAAP4 (Rahn, 2010), MELCOR (Gauntt et al., 2005) and RAIM (Wren et al., 1999; Kim and Cho, 2012), of these 3 are integral codes (ASTEC, MAAP4 and MELCOR), covering all aspects of severe accidents from initiating event through to release of FPs from the containment, with ASTEC providing the most detailed treatment and MAAP the fastest, most parametric, well suited to probabilistic safety studies by industry in which a large number of cases need to be run. ATHLET-CD provides a detailed model of core degradation of fission product release and transport, COCOSYS calculates detailed thermal hydraulic behaviour in the containment, while AIM is a detailed iodine chemistry model. ECART is a specialised thermalhydraulics/aerosol physics code, while INSPECT/IODAIR gives a detailed mechanistic treatment of iodine chemistry in the containment. RAIM is based on the semi-empirical IMOD methodology for iodine chemistry in the containment sump (Wren at al., 2009), and is used in conjunction with MELCOR. An integral calculation was also performed using ATHLET-CD and COCOSYS/AIM coupled together, see Table 1. For the base case, 23 calculations were received, with 3 for the optional best-estimate version. Of the base case calculations, 5 were integral (defined as including calculations for 3 or 4 phases).

\section{DESCRIPTION OF THE FPT3 TEST}

The in-reactor integral Phébus FP tests studied bundle degradation, release, transport and deposition of fission products, structural and control rod materials in the model primary circuit and containment building, under steam rich or steam-poor atmospheres, and under low pressures $(\sim 0.2$ $\mathrm{MPa}$ ), with specific attention to the behaviour of fission products, Figure 1 (Grégoire and Payot, 2009). The experimental facility scenario and objectives of the series have been extensively presented in literature, for example (Schwarz et al., 1999). 
The FPT3 test studied especially the impact of the boron carbide control rod on the fuel degradation and FP speciation and transport in steam poor condition. The FPT3 test sequence (Haste et al., 2010) involved heating of the bundle through a succession of power ramps and plateaux, leading to an oxidation runaway, further ramps and plateaux leading to fuel melting and relocation, with the degradation phase being terminated by reactor shutdown at $17370 \mathrm{~s}$ after the beginning of the heating phase, Figure 2. At the end of this phase the total amount of hydrogen released was $120 \pm 6 \mathrm{~g}$ ( 1 standard deviation), whilst the gas release coming from the $\mathrm{B}_{4} \mathrm{C}$ oxidation corresponds to $16 \mathrm{~g}$ of carbon dioxide and $17 \mathrm{~g}$ of carbon monoxide. The release fraction of the main volatile FPs ranges between $64 \%$ for Cs to around $80 \%$ of the initial bundle inventory (i.i.) for I and Te, whilst the semi and low volatile FPs release show a wider spread. A remarkable feature of the experiment was the substantial fraction of volatilised materials $(\mathrm{Cs}, \mathrm{Ag}, \mathrm{Mo}, \mathrm{Ru}$, and $\mathrm{Ba}$ ) which re-deposited on the intact upper part of the fuel rods (Grégoire and Haste, 2013).

The released material was swept by the coolant flow through the experimental circuit; deposition of aerosol and vapour in some parts of the circuits was measured, as well the flow rates of the different elements in the cold and hot leg. The deposition took place in the zones where thermal gradients are important, just above the fuel bundle and in the rising line of the steam generator. In this last zone, the mass deposited is enhanced by the formation of boron-rich blockages. The transported material was injected into $10 \mathrm{~m}^{3}$ vessel, simulating the containment building of a nuclear power plant. The $37 \mathrm{~h}$ aerosol phase started at 22,500 s when the containment was isolated. Airborne aerosols were deposited mainly by gravitational settling on the lower surface of the vessel. After about $51 \mathrm{~h}$ from the beginning of the transient, the aerosols deposited on the containment floor were washed out into the sump water. The 2 days chemistry phase started at the end of the washing phase; it was devoted to the analysis of iodine chemistry under conditions representative of LWR severe accidents, emphasising iodine speciation. An important objective of the experiment was to study the iodine behaviour in the containment vessel, in particular the amount and speciation - inorganic 
versus organic - of volatile iodine in the atmosphere. Another remarkable feature of the experiment was the very high iodine gas fraction $(\sim 90 \%)$ entering the containment during the transient, which determines the iodine behaviour in the short term in the containment atmosphere. In the long term the gaseous inorganic iodine release from the deposited aerosols radiolytic destruction becomes the main inorganic gaseous iodine contribution in the gaseous phase whereas the gaseous organic iodides contribution comes mainly from the radiolytic reaction of $I_{2}$ with paints, leading to the formation of organic iodides (RI), specifically methyl iodide.

\section{REPRESENTATION OF THE FACILITY}

A noding scheme was recommended in the specification report (Bieliauskas and Haste, 2011). In this scheme, the bundle is divided into 11 axial nodes while the number of radial rings is being left free as the number of thermal hydraulic flow channels. The minimum numbers of nodes recommended for the circuit was 12 , in order to obtain an adequate calculation of deposition. For the containment model suggested 14 nodes were suggested, but also 5 nodes could be used. The increase of nodes is not so important in the containment. This constituted the mandatory 'base case' calculation, in which it was intended that the participants would use .code options as for a plant study. A more detailed 'best-estimate' sensitivity study could also optionally be performed. For this case, the noding density was increased by typically a factor 2 or more at the choice of the user, and code options could be chosen to give a better match between calculated and observed results.

\section{ANALYSIS OF RESULTS}

The results were analysed in detail, comparing the results amongst each other and with FPT3 experimental data. There was considerable scatter amongst the results obtained from each code by different users, the 'user effect'. To minimise this effect, representative cases were selected where necessary, taking into account the quality of key output variables, completeness and accuracy of the 
technical reports, and including code developers where possible. This analysis led to an assessment of the main models in each of the four areas considered. The results are subdivided according to the four phases mentioned above. The best estimate cases simulations were plotted together with those of the base cases, given that the differences observed are not particularly significant.

\subsection{Bundle phase}

The physical processes occurred in this phase are strongly related on the bundle thermal behaviour. An accurate prediction of the fuel rod temperatures is essential for accurate calculation of the bundle degradation and fission product release, similar remarks apply to the control rod degradation for structural material release that forms the large part by mass of the aerosols transported into the circuit. Most of the participants assumed a reduction of the input nuclear power by about $10 \%$ and an increase of the shroud thermal conductivity, both within the experimental uncertainties. With these assumptions, the thermal behaviour of the fuel rods is rather well reproduced by the codes. Comparison between measured fresh fuel temperatures and results are illustrated in Figure 3 for an axial elevation of $500 \mathrm{~mm}$. The discrepancies during the thermal calibration of the bundle (until 7920 s) are mainly due to the lower input power selected for the simulation during this phase, whilst throughout the degradation phase a generally good overall agreement is observed up to the shutdown of the nuclear power at $17370 \mathrm{~s}$. Regarding the total hydrogen generation, the results given by different code simulations are consistent with experimental value $(120+/-6 \mathrm{~g})$; the beginning of the run-away phase is rather well described, to the experimental data, whilst the steam starvation duration tends to be underestimated, Figure 4 and Figure 5.

Although the bundle temperature evolution is quite well calculated, there are still great difficulties to reproduce the final degradation state of the bundle, Figure 6. The Phébus FPT3 test is the only test of the programme which used a $\mathrm{B}_{4} \mathrm{C}$ control rod. The suspected effects of spreading molten materials of the control rod towards fuel rods of the bundle and the $\mathrm{B}_{4} \mathrm{C}-\mathrm{SS}$ (boron carbide-stainless steel) eutectic 
formation and liquid $\mathrm{B}_{4} \mathrm{C}-\mathrm{SS}-\mathrm{Zr}$ relocation, are not accounted for in the codes, these phenomena cannot be neglected to simulate the observed bundle degradation behaviour.

The need for further code developments of the early phase of core degradation is recognized for the absorber rod material behaviour (Repetto et al., 2010). Therefore extensive programmes of separate-effect experiments have been performed, such as ISTP/BECARRE at Cadarache by IRSN (Clément and Zeyen, 2005; Dominguez and Drouan, 2014) under the International Source Term project and BOX, LAVA and QUENCH-SR at the Karlsruhe Institute of Technology (KIT), (Steinbrück et al., 2004) to enable a better understanding of $\mathrm{B}_{4} \mathrm{C}$ oxidation and interactions with cladding materials. As regards the control rod, the cumulative boron release is illustrated in Figure 7. The results show a wide spread, mainly due to the model adopted by the users notably for MELCOR, nevertheless the boron cumulative releases predicted by the ASTEC and ATHLET-CD codes are within a range of $\pm 10 \%$, even if the calculated kinetic of releases do not match the experimental data. The carbon gas speciation $\left(\mathrm{CH}_{4}, \mathrm{CO}, \mathrm{CO}_{2}\right)$ following the $\mathrm{B}_{4} \mathrm{C}$ oxidation needs attention, as theCH $\mathrm{H}_{4}$ production was correctly calculated as being low, but the fact that $\mathrm{CO}$ production is favoured in steam-poor periods $(<\sim 11000 \mathrm{~s})$ and $\mathrm{CO}_{2}$ in steam-rich $(>\sim 11000 \mathrm{~s})$ periods is not well captured overall, with a wide scatter in results (Figure 8 and Figure 9 for $\mathrm{CO}$ and $\mathrm{CO}_{2}$ respectively). ASTEC, unlike the other integral codes; does not currently output the speciation. The FP release from intact fuel and control rods followed by the release from the in-core molten pool, depends mainly on temperature and oxygen potential but also on various physical and chemical processes that occur within the fuel matrix and in the surrounding gaseous atmosphere. In the FPT3 test, the main fission products were basically classified according to the results of the VERCORS programme (Ducros et al., 2013) in where the results of VERCORS and Phébus FP were mainly consistent. The consequent classification is the following:

- Noble gases: Xe, Kr;

- Highly volatile fission products: I, Cs, $\mathrm{Rb}, \mathrm{Te}, \mathrm{Sb}, \mathrm{Ag}$; 
- Semi-volatile/low volatile fission products: $\mathrm{Mo}, \mathrm{Ba} / \mathrm{Ru}$,

In this experiment, the silver is released only as a fission product; in the earlier Phébus bundle tests the release is dominated from that from the $\mathrm{Ag} / \mathrm{In} / \mathrm{Cd}$ control rod there present.

Concerning the bundle release, all the experimental data were used for cross-checking, for statistical treatment, and for overall accuracy estimation. As a result the measured data fall within an estimated error band of $\pm 16 \%$ for gamma emitters (I, Te, Cs, $\mathrm{Ag}, \mathrm{Ru}, \mathrm{Ba}$ ) and $\pm 20 \%$ for Mo.

An important feature in the FPT3 post-test analysis was the significant deposition of several elements on the upper part of the fuel rods, see Table 2. The lower coolant flow along with the moderate bundle degradation in the test favoured this depositions, and in order to take into account this phenomenon the reference value used in the benchmark for $\mathrm{Mo}, \mathrm{Ba}, \mathrm{Ru}$ and $\mathrm{Cs}$ elements was the fuel release (bundle release + deposition in the bundle upper part).

Concerning the high volatile fission products; the total amounts released predicted by the codes are in agreement with experimental data, but generally the kinetics of release are too quick, see Figure 10 for I, and only the caesium release, tends to be overestimated, see Figure 11. The release of medium and low volatiles needs attention. The predicted results for molybdenum disagree with the measured data, showing a general tendency to overestimate the cumulative release. As seen in Figure 12 , the bundle and the fuel release show a large discrepancy, $23 \%$ and $53 \%$ respectively, thus approximately $30 \%$ of the Mo initial inventory is deposited in the upper part of the bundle; revaporisation of these deposits is possible later. Most of the codes cannot compute deposition in the upper part of the bundle, which affects strongly the total bundle release, in particular for Mo, Ru and $\mathrm{Ba}$, but also for the volatile Cs. Models that consider this phenomenon are necessary. MELCOR is the only code which can discriminate between the bundle and fuel release, but no participant provided this parameter. Concerning $\mathrm{Ba}$ and $\mathrm{Ru}$, the calculated releases vary greatly, ranging from to quite good to very poor. 
The good predictions of hydrogen production as well as the total amount of high volatile FPs released are important safety-relevant conclusion. The semi-volatile and low-volatile results are mainly consistent concerning the total amount released, but no code can predict correctly the release of all of these elements (Di Giuli et. al., 2013); the modelling could be improved; because a correct prediction is of extreme importance, either due to their radio-toxicity and influence on the residual power, or by their propensity to react with other fission products. The same considerations apply for structural materials, although they have no direct radiological significance, they potentially react with fission products, and their source terms are therefore necessary for accurate calculation of chemistry and transport in the circuit. Furthermore, the structural materials also form the bulk of the aerosol mass, affecting the aerosol concentration and the agglomeration processes. The user influence on predicted results can be noticed in most of the MELCOR cases, while ASTEC and ATHLET-CD submission show little differences amongst them.

\subsection{Circuit phase}

The injected steam flow swept FPs and structural materials (SMs) from the degrading fuel bundle through the circuit into the containment vessel. They were quantified by online instruments and by post-test analyses of the samples collected during the test. The experimental results tests shown, that all condensable FPs are transported through the simulated primary circuit in aerosol form, except iodine and cadmium that were detected mainly in gaseous form (Haste et. al. 2013). On their way through the primary circuit, the aerosols tend to deposit mainly where the temperature of the wall and fluid decrease strongly or where the flow is diverted: above the bundle, in the so-called upper plenum and vertical line and in the upstream part of the steam generator (SG) tube. The analyses of FP and structural material (SM) transport in the Phébus FPT3 tests for the entire circuit with the integral codes showed that the total deposited mass is underestimated on average by a factor 1.5 , as shown in Figure 13. Remarkable features of FPT3 test was the large deposition of boron-containing material 
between the hot leg and cold legs, with the potential of forming a partial blockage in the circuit (Haste et. al. 2012a). The main effect of this phenomenon was the reduction of the tube section, and the increase of the deposition surfaces, both effects enhance the FPs retention in the involved circuit zones, notably in upstream of the SG. No code could have reproduced these conditions and thus, the submitted results tend to underestimate the overall mass retention in the circuit. The boron deposition in the primary circuit is not considered so important regarding plant safety assessment. In a commercial PWR, the number of SG tubes is around 5000, and it is very unlikely that the boron contained in the water and in the control rods would form blockages in all the tubes at once. In Phébus FPT3 facility using only a single tube this phenomenon is more important and for a correct analysis of the results is necessary taking this effect into account. Nevertheless difficulties were also observed in capturing the thermophoretic deposition in the upper plenum for elements as Cs and Te, despite that the steam temperatures along the circuit were well predicted by most of the contributions. These discrepancies are mainly due to the wrong prediction or assumption chemical form of the FPs, and therefore their volatility. However, this is also not enough to explain the differences in the upper plenum. As regards molybdenum, the general overestimation of its bundle release meant that, the calculated total depositions along the system were in agreement with the measured one.

It is worth noting that work is already in progress to improve FP transport and deposition modelling in various codes. Regarding speciation, account is taken of the importance of caesium molybdates, while borates are also being considered. Similarly, in MELCOR 2.1, caesium molybdate has been introduced as the default fission product class for Cs (Herranz et al., 2015).

\section{3 lodine behaviour in the circuit}

The Phébus FPT3 test clearly provided new insights into the iodine transport through the primary circuit during a core meltdown accident for the iodine vapour speciation and for the transport of fractions of gaseous iodine into the containment. The circuit measurements for iodine were made 
with a total mass balance of only $68.1 \%$, this lack of mass balance made difficult a detailed comparison between experimental data and calculated results. Generally, the iodine mass retention factor of the circuit has been underrated on average of $40 \%$. The measured gaseous iodine fraction entering the containment was about 95\%, the highest among the Phébus FP tests carried out, while the submitted results predicted values around $2 \%$. This discrepancy has proved that the codes that used models based on equilibrium thermochemistry and/or user-defined fixed speciation are not able to predict the chemistry phenomena occurring during the transient, where it is suspected that nonequilibrium effects played a fundamental role, as indicated by existing studies for iodine (Herranz et al., 2015).

In order to improve the modelling of iodine chemistry in the primary circuit, particularly concerning the kinetics, an international research programme named CHIP (Chemistry of Iodine in the Primary circuit) was launched at IRSN Cadarache under ISTP, and modelling of kinetic limitations regarding iodine reactions is in progress in ASTEC/SOPHAEROS.

\subsection{Containment phase}

The containment analysis is focused on parameters that may have an impact on fission product behaviour in the containment, especially for aerosol physics. The prediction of the thermal hydraulic parameters in the containment as temperature, pressure, condensation rate, humidity, etc. was in generally satisfactory and, the small differences observed had probably only a weak influence on aerosol physics calculations, see Figure 14 for the condensation rate.

The evolution of the aerosol airborne mass largely depends on the quality of structural material and FP (Cs, Mo) releases calculation, for integral submissions. All the integral calculations tend to underestimate the total SM and FP deposition in the circuit and to overestimate the Mo and Cs release, this combination (along with the blockage effect mentioned above) leading to an 
overestimation of the total airborne mass entering the containment, making the comparison between experimental data and integral results unreliable, Figure 15.

Figure 16 and Figure 17 show the aerosol airborne mass inside the containment during the transient, for the integral and stand-alone cases respectively. The stand-alone calculations use as input the experimental data. As can be seen, the large aerosol mass predicted by the integral calculations lead to a faster depletion rate whilst the stand-alone best results show good agreement with experimental values. The faster depletion rate is due to the higher concentration of aerosol, which leads to more agglomeration in the containment. Given this discrepancy, no clear conclusion could be drawn on the relative importance of the main depletion processes in the experiment (diffusiophoresis and gravitational settling) for the integral cases; the results predict a greater deposited mass by gravitational settling than by diffusiophoresis at least 7 times greater, as against about 2 times greater in the data. This merits further investigation.

\subsection{Chemistry phase}

The dominant phenomena for iodine chemistry in the containment during FPT3 test were:

- The fraction of iodine exiting the circuit as gas phase;

- The interaction of iodine with painted surfaces, including adsorption, desorption, and organic iodide formation and destruction;

- The destruction of iodine species in the atmosphere by radiolytic processes;

All of these have a strong influence on the gaseous iodine concentration in the containment atmosphere, which is the most important safety-related parameter. For the integral cases, the first phenomenon is very difficult to predict, because the calculations of iodine chemistry use the results of release, transport and aerosol behaviour in the containment. There is therefore a risk of propagation of errors when estimating the gaseous iodine concentration in the containment 
atmosphere that is a key factor for the safety studies. Iodine interaction with painted surfaces and the destruction by radiolytic processes determine the quasi steady-state level in gaseous iodine concentration measured in the experiment before and after the washing phase. Regarding the transport of gaseous iodine in the primary circuit, none of the codes is able to reproduce what was experimentally observed, even those having chemistry modelling. Given this difficulty in predicting the iodine source to the containment in the integral cases, only the stand-alone cases with iodine source input based on the test data were analysed.

The iodine deposition on painted surfaces, $54 \%$ containment inventory, was well predicted, Figure 18, while there were greater discrepancies with the organic iodine fraction in the gas phase, Figure 19 (from iodine interactions with paint in the long term) with a tendency to overestimation in the long term. The RI is more difficult to remove by containment sprays or by filtration than $\mathrm{I}_{2}$, in any case the results are conservative. Inorganic iodine was rather better predicted than organic iodine, Figure 20. Overall, the behaviour of gaseous iodine in the containment, assuming that its predominant form entering the containment is inorganic, is quite satisfactorily reproduced in the better code calculations.

\section{IMPACT ON FUTURE RESEARCH PROGRAMS}

In order to gain more understanding about severe accident phenomena and to improve code models, international experimental programs have been/are being carried out. For the effects studied in FPT3, and more generally in Phébus FP, the most relevant are:

- BECARRE experiments (2005-2010) performed by IRSN (Dominguez and Drouan, 2014) in the framework of the International Source Term Program (ISTP) (Clément and Zeyen, 2005), devoted to boron carbide effects on core degradation, as well as corresponding tests carried out at Karlsruhe Institute of Technology (BOX, LAVA, QUENCH-SR) under the German national programme (Steinbrück, 2010);

- VERDON series (Ducros et al, 2013), being performed by CEA under ISTP, and the completed VERCORS series (Pontillon et al., 2010) also by CEA, which study/studied FP release and transport; 
- $\quad$ CHIP program being performed by IRSN (Haste et al., 2012b) under ISTP, to provide data on the physico-chemical transformations of iodine in the primary circuit, including kinetics, for example considering the systems $\{\mathrm{Mo}, \mathrm{Cs}, \mathrm{I}, \mathrm{O}, \mathrm{H}\}$ and $\{\mathrm{B}, \mathrm{Cs}, \mathrm{I}, \mathrm{O}, \mathrm{H}\}$;

- $\quad$ EPICUR experiments, performed by IRSN under ISTP (Haste et al., 2012b) and continuing under the OECD/STEM project (www.oecd-nea.org/nsd), OECD/BIP projects on behaviour of iodine in the containment, and the earlier PARIS project (Bosland et al., 2008), completed by AREVA in collaboration with IRSN to provide experimental data on the physicochemical transformations of iodine (formation and destruction of volatile iodine species) under irradiation in the reactor containment. Particular importance is accorded to the absorption/desorption of iodine on painted surfaces under irradiation, to the stability under radiation of deposited iodide aerosols and to gas phase iodine oxidation reactions;

- $\quad$ THAI experiments, performed by Becker Technologies and their predecessors under German national funding (Weber et al., 2010) then/now under OECD projects (www.oecd-nea.org/nsd), on the effects of thermal hydraulics on iodine behaviour and on iodine interactions with surfaces and aerosols in the containment.

These concern source term, with the exception of the first. Other priority research areas identified in SARNET indicated in (Klein-Heßling et al., 2014), such as reflood behaviour, in-vessel melt retention generally, and ex-vessel phenomena such as molten-core concrete interactions, are out of scope here, as these issues are not addressed in the Phébus FP programme. An example regarding how all available data are taken into account regarding code validation and development is given in (Chatelard et al., 2014) for the ASTEC code, a similar approach is adopted here.

It is thus concluded that the areas identified where modelling improvements are recommended have been or are being covered by relevant experimental programmes, which can form the basis for such code developments, e.g. for kinetics of iodine reactions in the primary circuit. When these have been completed, new benchmarks based on Phébus FP data (e.g. comparing predictions on FPT1, FPT2 and FPT3 under the same modelling assumptions) and on THAI (e.g. on THAI-Iod30 where painted surfaces will be introduced) are planned to assess this progress using independent data, and to see what further research needs to be done, for example under the aegis of the NUGENIA Association (www.nugenia.org). In formulating these benchmarks, the need to account for user effects as noted here and in the THAI Iod-11/Iod-12 exercise (Haste et al., 2014) will be carefully considered. 


\section{CONCLUSION}

The SARNET benchmark on Phébus FPT3 has provided many insights on the ability of severe accident codes to calculate the different phases of an accident sequence in an integral manner.

Several areas where code improvements are recommended have been identified, the main ones are:

- models taking into account the B-SS-Zr interaction during the core degradation;

- a better estimation of structural material release, especially for tin from Zircaloy cladding, and of semi/low volatile release;

- the possibility to take into account the presence of gaseous iodine in the RCS.

These are being taken into account in current research programmes.

Another remarkable point of the FPT3 benchmark is the strong user effect observed, therefore the user effect in plant studies cannot be ruled out. A major objective must be to limit its consequences on the quality of the study. It is recommended that this could be achieved using adequate procedures for controlling the results, using the code default parameters/models and perform sensitivity analyses changing one default parameter/model at once, in order to better understand its effect on the obtained results. The quality of the models must also be taken into account. Severe accident codes are difficult to handle, and the validation is not complete. They should not be interpreted as black boxes; the users should not trust automatically the results of their calculation. A critical analysis should always be undertaken, to see if the results seem consistent and reasonable.

\section{ACKNOWLEDGMENTS}

The Phébus FP program was initiated in 1988 by IRSN, in cooperation with the Commisariat à l'Énergie Atomique et aux Énergies Alternatives (formerly the Commisariat à l'Énergie Atomique) (CEA) and the Commission of the European Communities (EC), with 
contributions from Electricité de France (EdF), the United States Nuclear Regulatory Commission (USNRC), the CANDU Owners Group of Canada, the Japanese Nuclear Energy Society (JNES), the Japanese Atomic Energy Agency (JAEA), the Korean Atomic Energy Research Organization (KAERI), the Swiss Nuclear Inspectorate (ENSI, formerly HSK) and the Paul Scherrer Institute (PSI) of Switzerland. The SARNET Network of Excellence was part-funded under the European Commission $7^{\text {th }}$ Framework Program (2007-2013) under grant agreement 231747. The authors thank J. Fleurot, D. Jacquemain and J.-P. Van Dorsselaere of IRSN for their careful reviews of this paper.

\section{REFERENCES}

Allelein, H.-J., Arndt, S., Klein-Heßling, W., Schwarz, S., Spengler, C., Weber, G., 2008, "COCOSYS: status of development and validation of the German containment code system", Nucl. Eng. Des. 238, 872-889.

Bieliauskas, A., and Haste, T., 2011. Specification of SARNET2 FPT3 benchmark (revision 2). IRSN internal document, June.

Bosland, L., Funke, F., Girault, N., Langrock, G., 2008. PARIS project: radiolytic oxidation of molecular iodine in containment during a nuclear reactor severe accident. Part 1. Formation and destruction of air radiolysis products - experimental results and modelling, Nucl. Eng. Des. 238 , pp. $3542-3550$.

Broughton, J. M., Kuan, P., Petti, D. A., Tolman, E. L., 1989. A scenario of the Three Mile Island unit 2 accident. Nucl. Technol. 87, 34-53. 
Chatelard, P. et al., 2014. Overview of the independent ASTEC V2.0 validation by SARNET partners, Nucl. Eng. Des. 272, 136-151.

Clément, B., Zeyen R., 2005. The Phebus fission product and source term international programs, In: Proc. Int. Conf. Nucl. Energy for New Europe Bled (Slovenia), 5-8 September.

Clément, B., Haste, T., Krausmann, E., Dickinson, S., Gyenes, G., Duspiva, J., de Rosa,F., Paci, S., Martin-Fuertes, F., Scholytssek, W., Allelein, H.-J., Guntay, S., Arien, B., Marguet, S., Leskovar, M., Sartmadjiev, A., 2005. Thematic network for Phébus FPT1 international standard problem (THENPHEBISP). Nucl. Eng. Des. 235, 347-357.

Clément, B., Zeyen, R., 2013. The objectives of the Phébus FP experimental programme and main findings, Ann. Nucl. En. 61, 4-10.

Dickinson, S. and Sims, H. E., 2000, Development of the INSPECT model for the prediction of iodine volatility from irradiated solutions, Nucl. Technol. 129, 374-386,

Dominguez, C., Drouan, D., 2014. Degradation in steam of $60 \mathrm{~cm}$-long B 4 C control rods, J. Nucl. Mat. 451, 111-119.

Di Giuli, M., Haste, T., Biehler, R., 2013. Final comparison report on the Phébus FPT3 benchmark, IRSN/SARNET2 internal document, December. 
Ducros, G., Pontillon, Y., Malgouyres, P.P., 2013. Synthesis of the VERCORS experimental programme: Separate-effect experiments on fission product release, in support of the PHEBUS-FP programme. Ann; Nucl. En. 61, 75-87.

Gauntt, R.O., Cash, J.E., Cole, R.K., Erickson, C.M., Humphries, L.L., Rodriguez, S.B., Young, M.F., 2005, “MELCOR Computer Code Manuals, vol. 1, Primer and Users' Guide, vol. 1”. Sandia National Laboratories, NUREG/CR-6119, Rev. 3.

Grégoire, A.-C., Payot, F., 2009. Phébus FPT2 test: Overview of fission product and material release and transport in the experimental circuit. In: International Conference on Advanced Power Plants 2009, Tokyo, Japan, May 10-14, Paper 9310.

Grégoire, A.-C., Haste, T., 2013. Material release from the bundle in Phébus FP, Ann. Nucl; En. 61, 63-74.

Haste, T., Payot, L., Bosland, L., Clément, B., Girault, N., 2010. Main outcomes of fission product behavior in the Phébus FPT3 test. In: Proc. 4th European Review Meeting on Severe Accident Research (ERMSAR-2010) Bologna Italy, 11-12 May.

Haste, T, Payot, F, Dominguez, Ch., March, Ph., Simondi-Teissere, B., Steinbrück, M., 2012a. Study of boron behavior in the primary circuit of water reactors under severe accident conditions: A comparison of Phébus FPT3 results with other recent integral separate-effects data. Nucl. Eng. Des. 246, 147-156. 
Haste, T., Auvinen, A., Cantrel, L., Kalilainen, J., Kärkelä T., Simondi-Teisseire, B., 2012b, Progress with iodine chemistry studies in SARNET2. ISBN 978-961-6207-35-5, In: Proc. Int. Conf. Nucl. Energy for New Europe, Ljubljana (Slovenia), 5-7 September.

Haste, T., Payot, F, Bottomley, P.D.W, 2013. Transport and deposition in the Phébus FP circuit. Ann. Nucl. En. 61, 102-121.

Haste, T., Di Giuli, M., Weber, G., Weber, S., 2014. Iodine Benchmarks in the SARNET Network of Excellence, ISBN 978-961-6207-37-9, In/ Proc. Int. Conf. Nucl. Energy for New Europe, Portorož (Slovenia), 8-11 September.

Herranz, L., Haste, T., Kärkelä, T., 2015. Recent advances in the source term area within the SARNET European severe accident research network. Nucl. Eng. Des. 288, 56-74.

Kim, H.-C., Cho, S.-W., 2012, "Simulation of Iodine Behavior by Coupling of a Standalone Model with MELCOR”, Trans. Korean Nuclear Society, Spring Meeting, Jeju, Korea, 17-18 May.

Klein-Heßling, W. et al., 2014. Conclusions on severe accident research priorities, Ann. Nucl. En. 74, 4-11.

March, P., Simondi-Teisseire, B., 2013. Overview of the facility and experiments performed in Phébus FP. Ann. Nucl. En. 61, 11-22. 
Parozzi, F., Paci, S., 2006, Development and validation of the ECART code for the safety analysis of nuclear installations, In: Fourteenth International Conference on Nuclear Engineering 2006, Miami, United States, July 17-20 2006.

Payot, F., Haste, T., Biard, B., Bot-Robin, F., Devoy, J., Garnier, Y., Guillot, J., Manenc, Ch., March, P., 2011. FPT3 Final Report, IRSN Document Phébus PF IP/11/589, DPAM/DIR-2011.

Pontillon, Y., Ducros, G., Malgouyres, P.P., 2010. Behaviour of fission products under severe PWR accident conditions: VERCORS experimental programme-Part 1: General description of the programme, Nucl. Eng. Des. 240(7), 1843-1852.

Rahn, F., 2010. Technical foundation of reactor safety—knowledge base for resolving severe accident issues. Electric Power Research Institute, Final Report, 1020497.

Repetto, G., De Luze, O., Drath, T., Koch, M. K., Hollands, T., Trambauer, K., Bals, C., Austregesilo, H., Birchley, J. 2010. Analyses of the Phébus FPT3 experiment using the severe accident codes ATHLET-CD, ICARE/CATHARE and MELCOR, Nucl. Technol. 176, 352370.

Schwarz, M., Hache, G., von der Hardt, P., 1999. Phébus FP: a severe accident research programme for current and advanced light water reactors. Nucl. Eng. Des. 187, 47-69. 
Steinbrück, M., 2010. Degradation and oxidation of $\mathrm{B}_{4} \mathrm{C}$ control rod segments at high temperatures, J. Nucl. Mater. 400, pp. 138-150, and references therein.

Trambauer, K. et al, 2011. ATHLET-CD Mod 2.2 Cycle B - User's Manual, GRS-P-4/Vol. 1, GRS.

Van Dorsselaere, J.P., Seropian, C., Chatelard, P, Jacq, F., Fleurot, J., Giordano, P., Reinke, N., Schwinges, B., Allelein, H.J. and Luther, W., 2009, The ASTEC integral code for severe accident simulation, Nucl. Technol. 165, 293-307.

Van Dorsselaere, J.-P., Auvinen, A., Beraha, D., Chatelard, P., Herranz, L.E., Journeau, C., KleinHessling, W., Kljenak, I., Miassoedov, A., Paci, S., Zeyen, R., 2015, Recent severe accident research synthesis of the major outcomes from the SARNET network, . Nucl. Eng. Des. 291, 19-34. von der Hardt, P., Jones, A. V., Lecomte, C., Tattegrain, A, 1994. Nuclear Safety Research: The Phébus FP severe accident experimental program. Nuclear Safety 35(2), 187-205.

Weber, G. and Funke, F., 2009, "Description of the iodine model AIM-3 in COCOSYS", Technical Report GRS-A-3508, GRS Garching, Germany.

Weber, G., Funke, F., Poss, G. 2010. Iodine transport and behaviour in large-scale THAI tests. In: Proc. 4th European Review Meeting on Severe Accident Research (ERMSAR-2010), Bologna (Italy), 11-12 May.

Wren, J.C., Glowa, G.A. and Ball, J.M., 1999, A simplified model for containment iodine chemistry and transport: model description and validation using stainless steel RTF test results, In: Proc. OECD Workshop on Iodine Aspects of Severe Accident Management, May 18-20, Vantaa, Finland, OECD/NEA/CSNI/R(99)7. 


\section{List of table titles}

Table 1 : Summary of submissions for the Phébus FPT3 benchmark

Table 2 : Release of fission products, actinides and structural material in the Phébus FPT3 experiment 


\section{List of figure titles}

Figure 1: Simplified layout of the Phébus FPT3 test train showing relationship with a LWR

Figure 2: Schematic test sequence for Phébus FPT3, with bundle initial and final states

Figure 3: Fresh fuel temperature at $500 \mathrm{~mm}$ axial elevation

Figure 4: Hydrogen mass flow rate

Figure 5: Hydrogen integrated production

Figure 6: Phébus FPT3 bundle final linear axial mass distribution

Figure 7: Boron release from the bundle

Figure 8: Carbon monoxide integrated production

Figure 9: Carbon dioxide integrated production

Figure 10: Molybdenum release from the fuel and bundle

Figure 11: Caesium release from the fuel and bundle

Figure 12: Molybdenum release from the fuel and bundle

Figure 13: Overall mass retention of the fission products I, Cs, Te, Mo in the circuit 
Figure 14: Containment condensation rate

Figure 15: Aerosol speciation and mass entering the containment

Figure 16: Total aerosol airborne mass integral cases

Figure 17: Total aerosol airborne mass stand-alone case

Figure 18: Iodine mass deposited on painted surfaces

Figure 19: Organic iodine mass in containment atmosphere gas phase

Figure 20: Inorganic iodine mass in containment atmosphere gas phase 


\begin{tabular}{|c|c|c|c|}
\hline Organisation & Code & Phase & Country \\
\hline CIEMAT & ASTEC v2.02 & 3 & Spain \\
\hline EDF & MAAP 4.07 & 1 & France \\
\hline ENEA & MELCOR 1.8.6 & 1,2 & Italy \\
\hline ENEA & ASTEC & 1,2 & Italy \\
\hline GRS & ATHLET/COCOSYS coupled & $\mathrm{A}$ & Germany \\
\hline GRS & ATHLET-CD 2.2B & 1,2 & Germany \\
\hline GRS & COCOSYS V2.4beta & 3,4 & Germany \\
\hline IRSN & ASTEC v2.0 rev1 p2 beta & $\mathrm{A}$ & France \\
\hline IRSN & ASTEC v2.0 rev2 p $/$ IODE* & 4 & France \\
\hline NNL & INSPECT2k/IODAIR-v3 & 4 & United Kingdom \\
\hline NUBIKI & MELCOR 1.8.6YT & 3 & Hungary \\
\hline RUB & ATHLET-CD2.2A & 1,2 & Germany \\
\hline UNIPI & ASTEC v2.0 rev.2 & 1,3 & Italy \\
\hline UNIPI & MELCOR 1.8.5 & 1,3 & Italy \\
\hline USNRC & MELCOR 2.1 & 1 & United States \\
\hline VUJE & ASTEC v2.0 rev2 p1 & $\mathrm{A}$ & Slovakia \\
\hline TUS & ASTEC v.2.0 & 3,4 & Bulgaria \\
\hline KAERI & MELCOR 1.8.6 YT & $1,2,3$ & Republic of Korea \\
\hline RSE & ECART & 3 & Italy \\
\hline RSE & MELCOR 1.8.6 YN & 3 & Italy \\
\hline UJV & ASTEC v2.0 rev1 p2 beta & $\mathrm{A}$ & Czech Republic \\
\hline UJV & ASTEC v2.0 rev1 p2 beta & 3 & Czech Republic \\
\hline UJV & ASTEC v2.0 rev1 p2 beta & 4 & Czech Republic \\
\hline UJV & MELCOR 1.8.6 YV patch 3481 & $1,2,3$ & Czech Republic \\
\hline UJV & MELCOR 1.8.6 YV patch 3481 & 3 & Czech Republic \\
\hline KINS & MELCOR 1.8.5/RAIM & 4 & Republic of Korea \\
\hline
\end{tabular}

Phase: 1-4 = bundle, circuit, containment, chemistry respectively; A = all (full integral calculation); 26 calculations in all. * Improved version intended for ASTEC v2.1.

Table 1 : Summary of submissions for the Phébus FPT3 benchmark 


\begin{tabular}{|c|c|c|c|}
\hline Released element & $\begin{array}{c}\text { Bundle release } \\
\text { (\% initial inventory) }\end{array}$ & $\begin{array}{l}\text { Deposition in the } \\
\text { bundle upper part } \\
\text { (\% initial inventory) }\end{array}$ & $\begin{array}{c}\text { Fuel release } \\
\text { (\% initial inventory) }\end{array}$ \\
\hline \multicolumn{4}{|l|}{ Noble qases } \\
\hline $\mathrm{Kr}$ & 72 & 0 & 72 \\
\hline $\mathrm{Xe}$ & 84 & 0 & 84 \\
\hline \multicolumn{4}{|l|}{ Volatiles } \\
\hline Cs & 64 & 9 & 73 \\
\hline I & 79 & 1 & 80 \\
\hline $\mathrm{Te}$ & 80 & 1 & 81 \\
\hline $\mathrm{Sb}$ & 40 & n.d & 40 \\
\hline $\mathrm{Ag}$ & 70 & 27 & 70 \\
\hline $\mathrm{Rb}$ & 35 & n.d & 35 \\
\hline $\mathrm{Cd}$ & $>40$ & n.d & $>40$ \\
\hline \multicolumn{4}{|l|}{ Semi/low volatiles } \\
\hline Mo & 23 & 30 & 53 \\
\hline $\mathrm{Ba}$ & 6 & 5 & 11 \\
\hline $\mathrm{Ru}$ & 1 & 7 & 8 \\
\hline $\mathrm{Sr}$ & 0.05 & n.d. & 0.05 \\
\hline $\mathrm{La}$ & $>0.059$ & n.d. & $>0.059$ \\
\hline $\mathrm{Ce}$ & 0.28 & n.d. & 0.28 \\
\hline \multicolumn{4}{|l|}{ Actinides } \\
\hline $\mathrm{U}$ & $>0.011$ & n.d. & $>0.011$ \\
\hline $\mathrm{Pu}$ & $>0.0009$ & n.d. & $>0.0009$ \\
\hline \multicolumn{4}{|c|}{$\begin{array}{c}\text { Control rods and structural } \\
\text { materials }\end{array}$} \\
\hline $\mathrm{B}$ & 78 & n.d. & \\
\hline $\mathrm{Sn}$ & $>29$ & n.d. & \\
\hline
\end{tabular}

Table 2 : Release of fission products, actinides and structural material in the Phébus FPT3 experiments n.d. $=$ not detected 


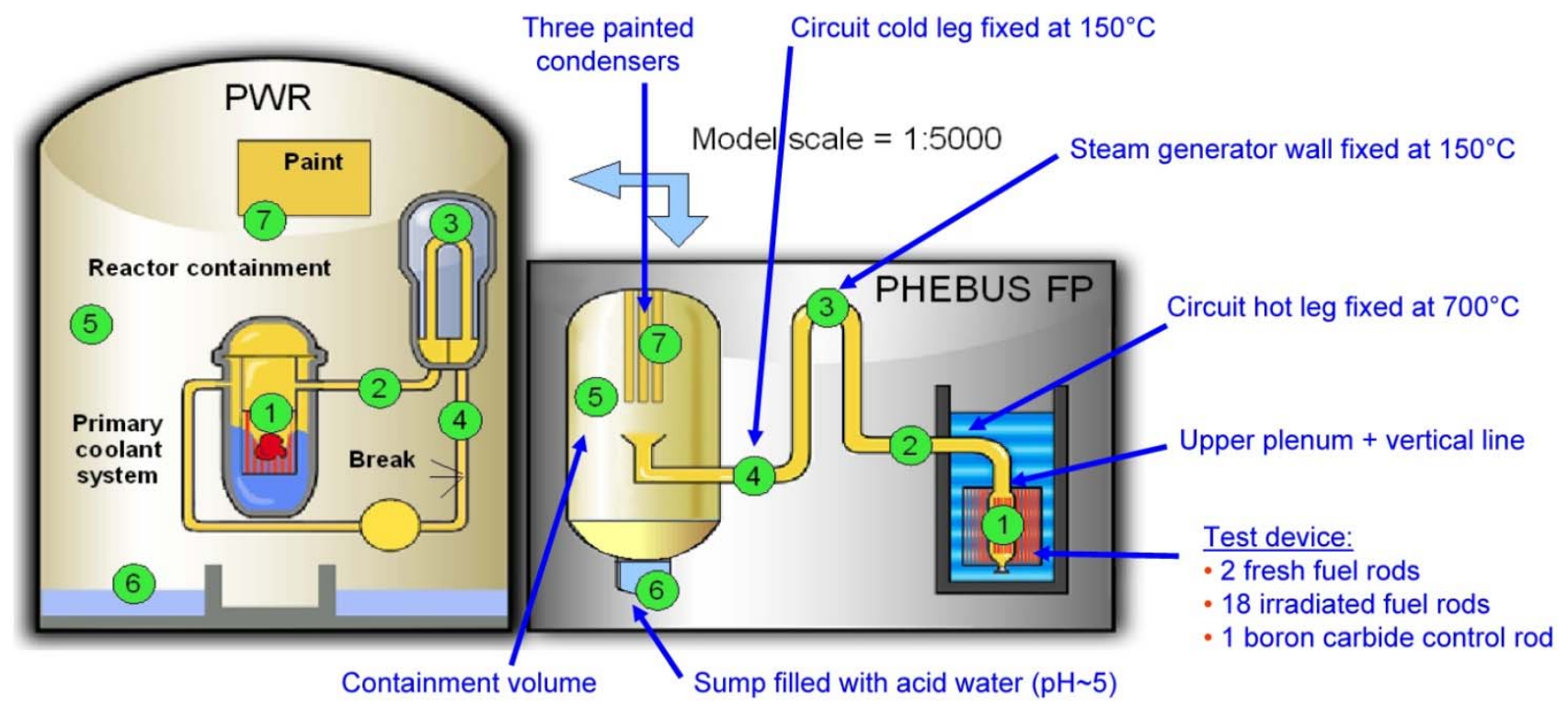

Figure 1: Simplified layout of the Phébus FPT3 test train showing relationship with a LWR (Grégoire and Payot, 2009)

(Key : (1), fuel bundle; (2), primary circuit hot leg; (3), steam generator; (4), primary circuit cold leg; (5), containment building; (6), sump; 7, dry and wet condensers)

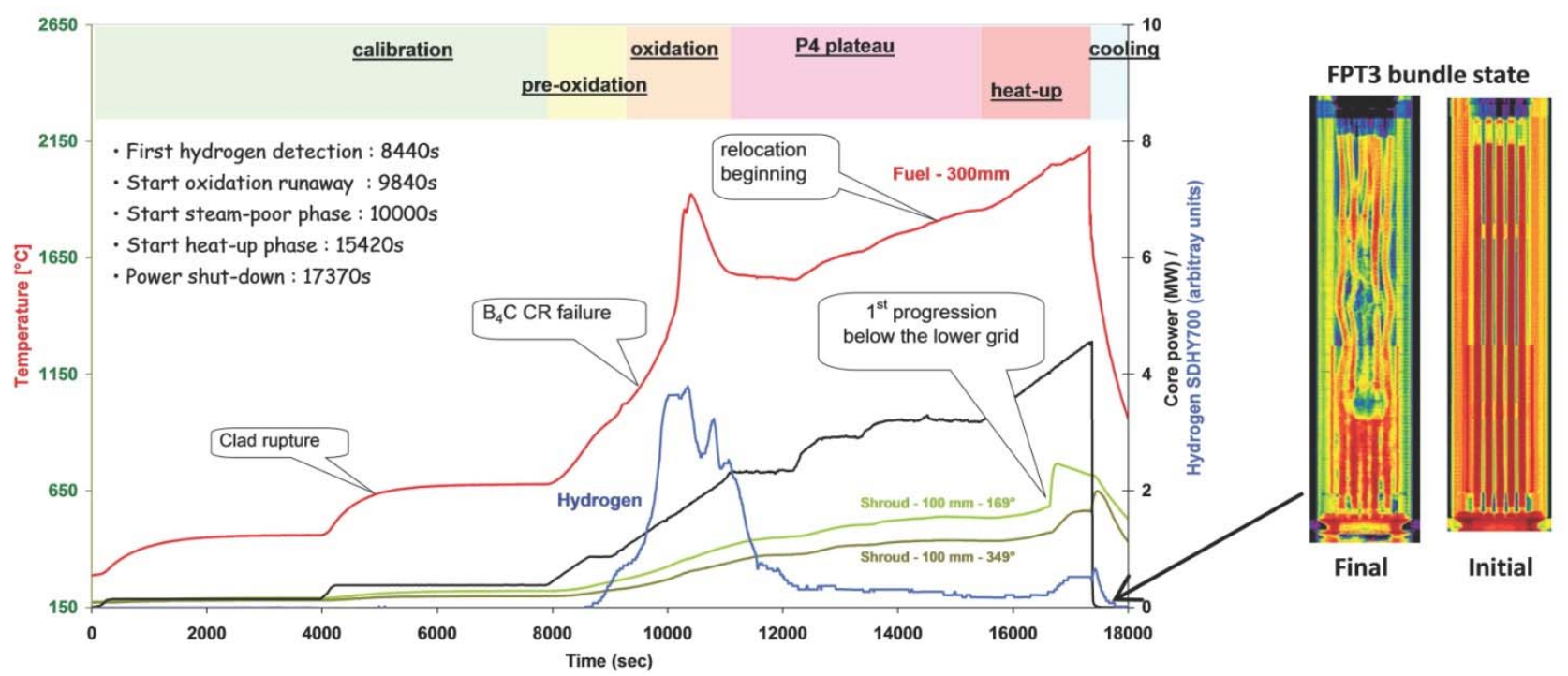

Figure 2: Schematic test sequence for Phébus FPT3, with bundle initial and final states (adapted from Payot et al., 2011) 


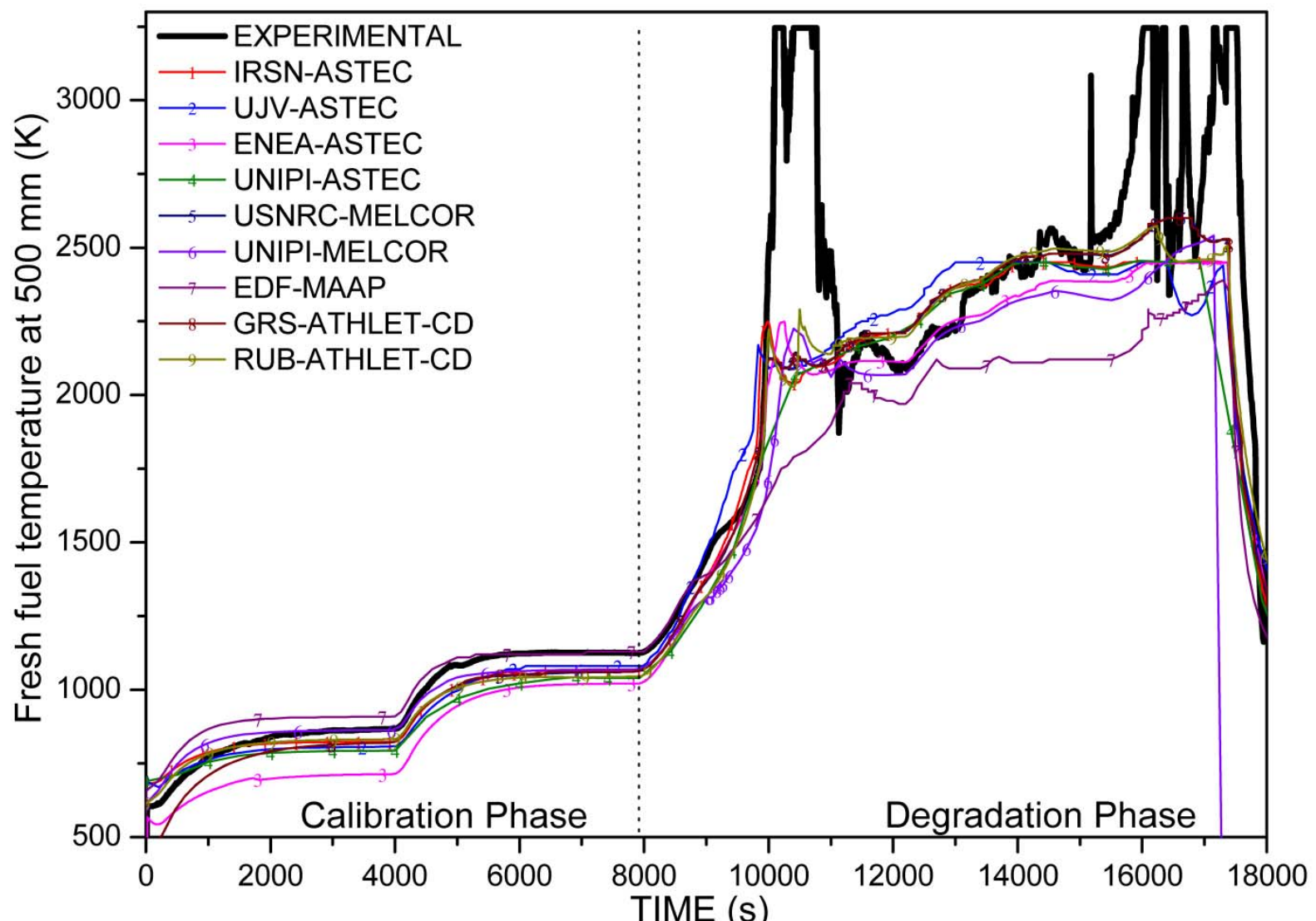

Figure 3: Fresh fuel temperature at $500 \mathrm{~mm}$ axial elevation 


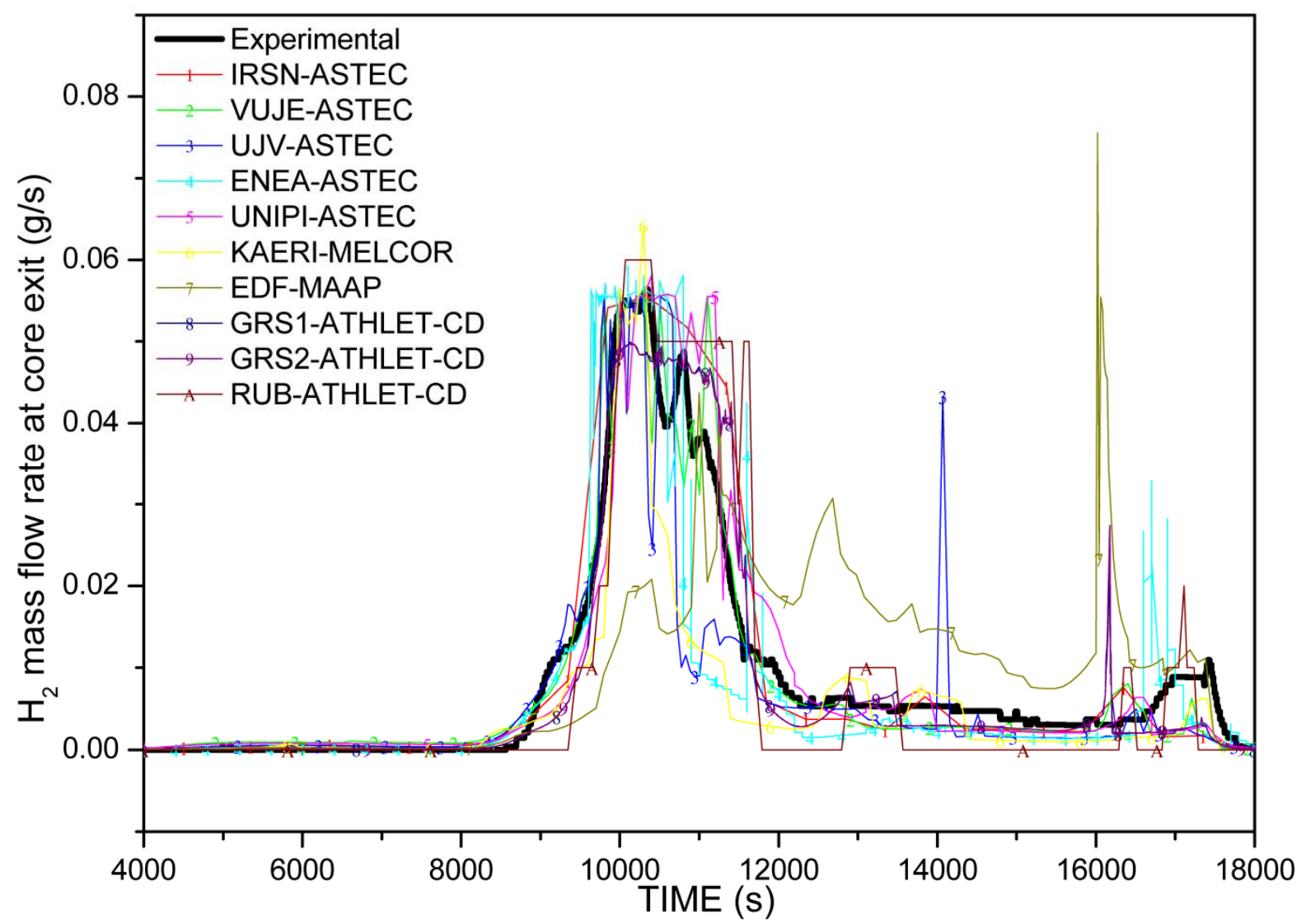

Figure 4: Hydrogen mass flow rate

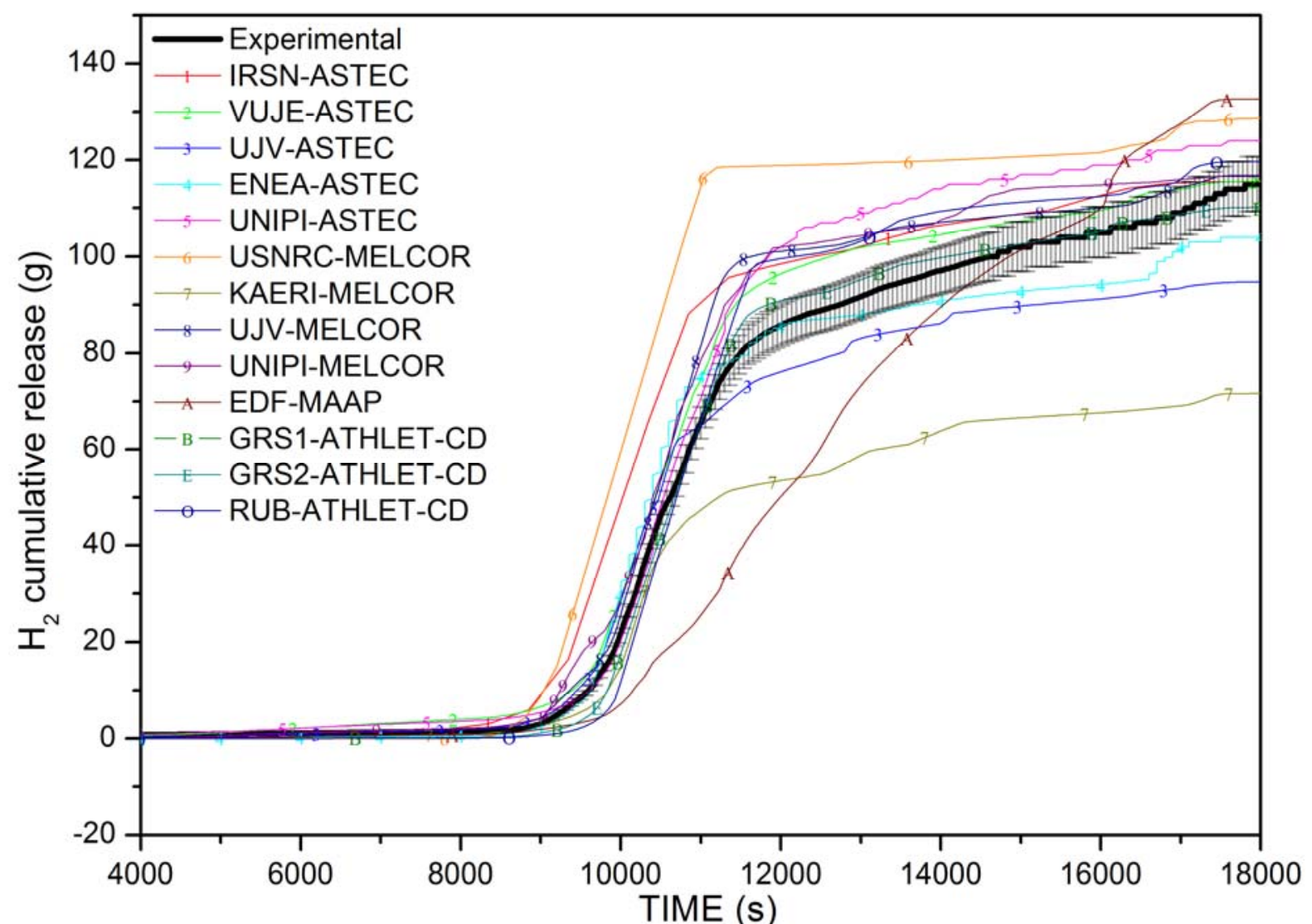

Figure 5: Hydrogen integrated production 


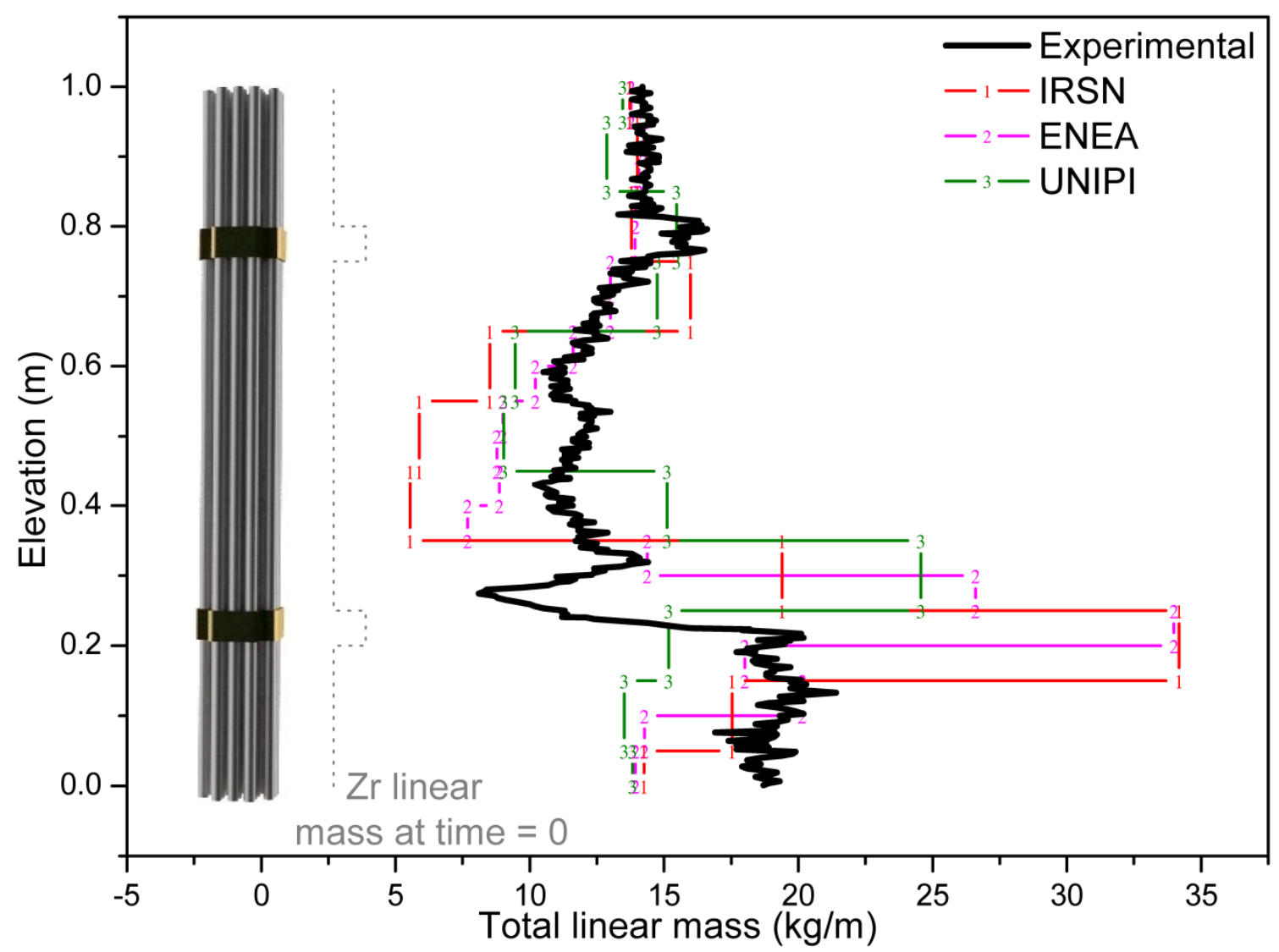

Figure 6: FPT3 bundle final linear axial mass distribution

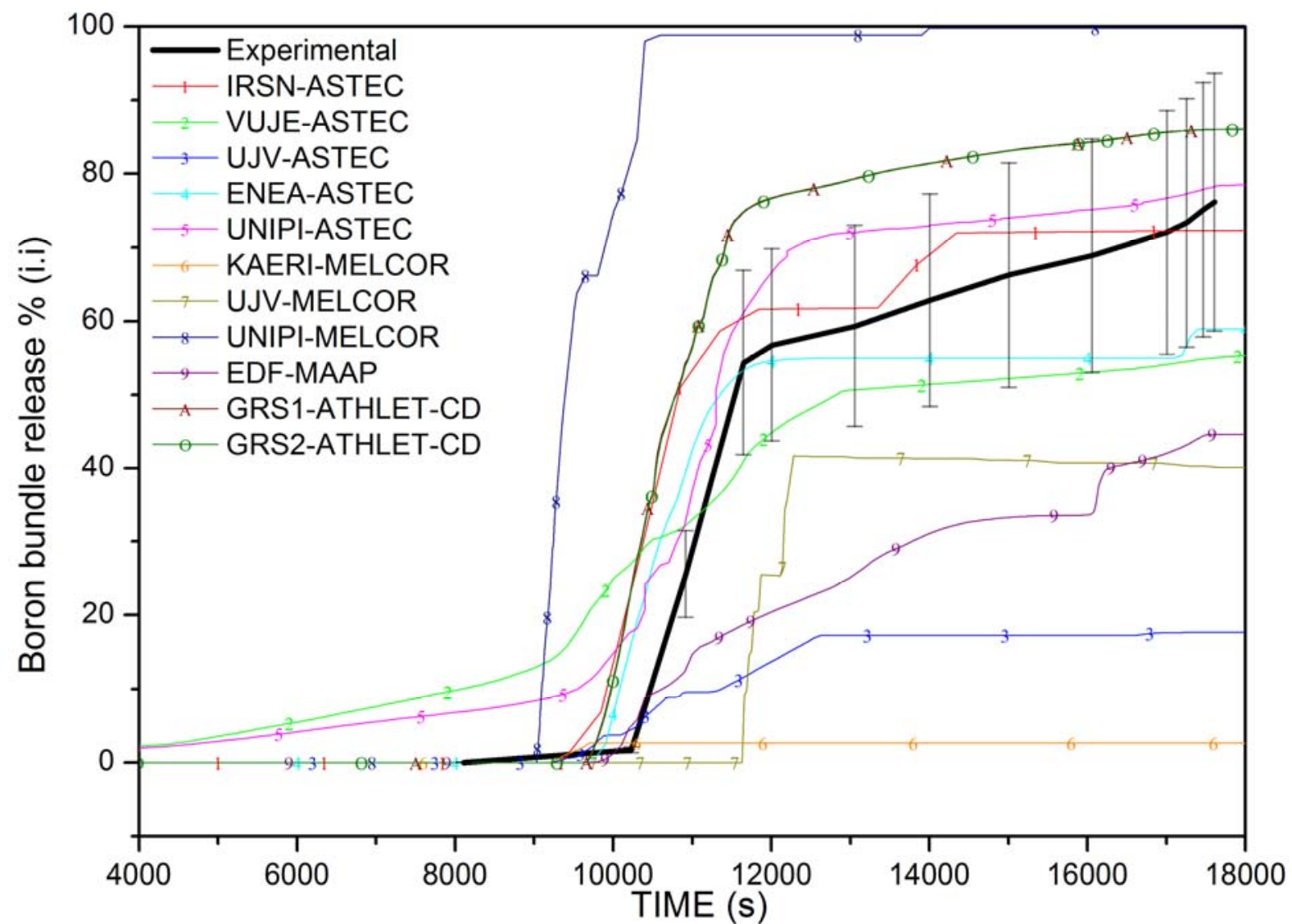

Figure 7: Boron release from the bundle 


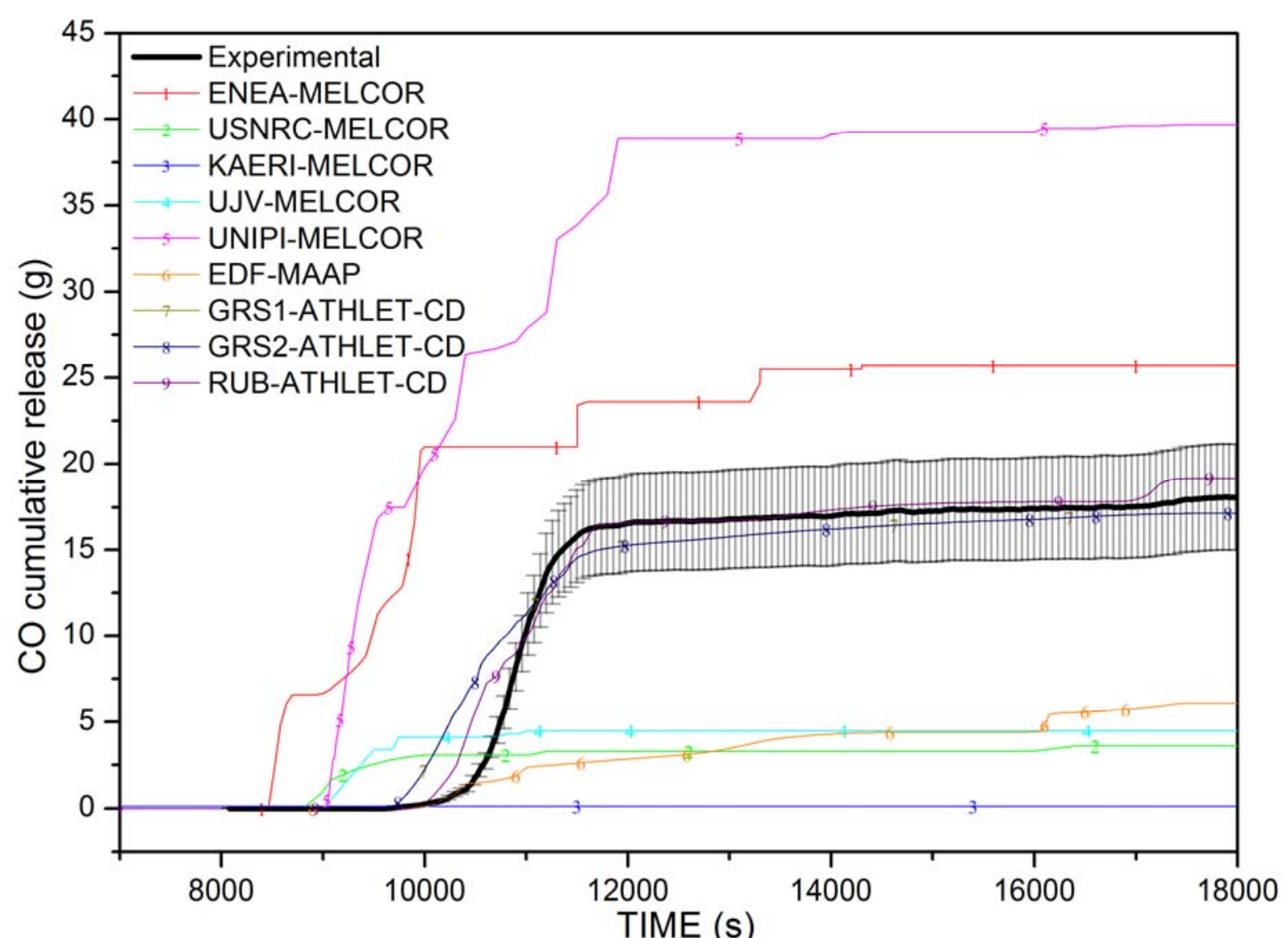

Figure 8: Carbon monoxide integrated production

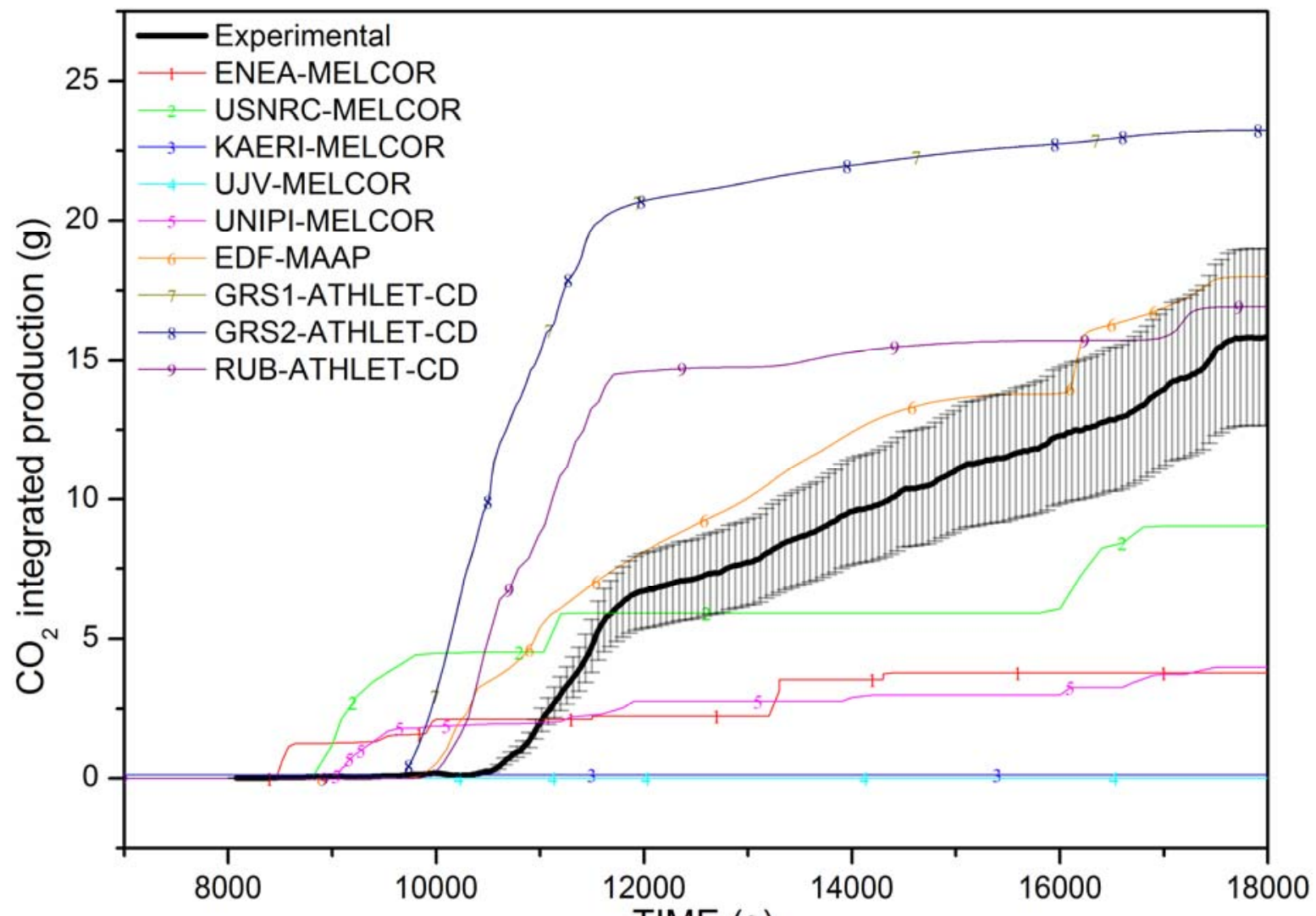

Figure 9: Carbon dioxide integrated production 


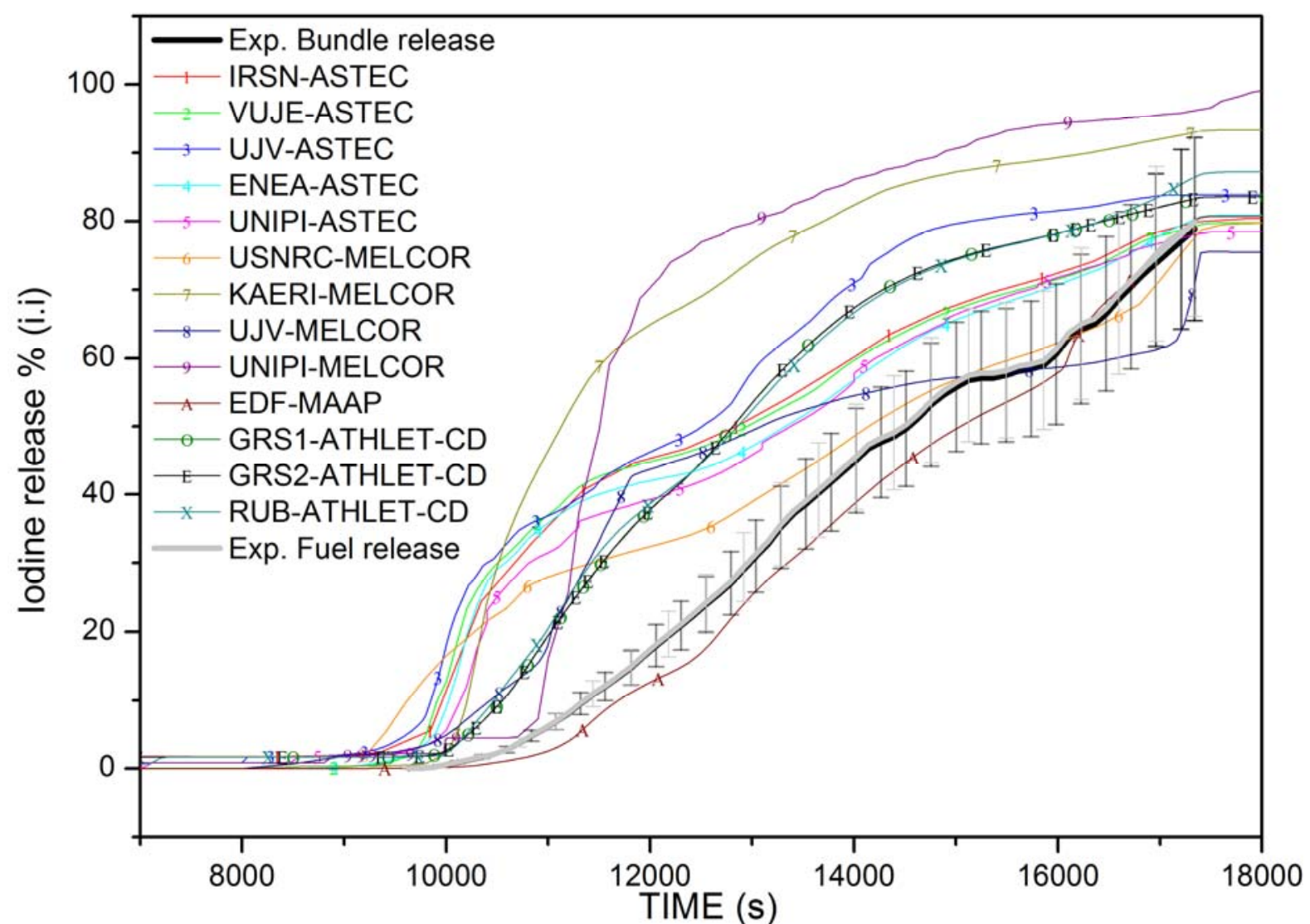

Figure 10: Iodine release from the fuel and bundle

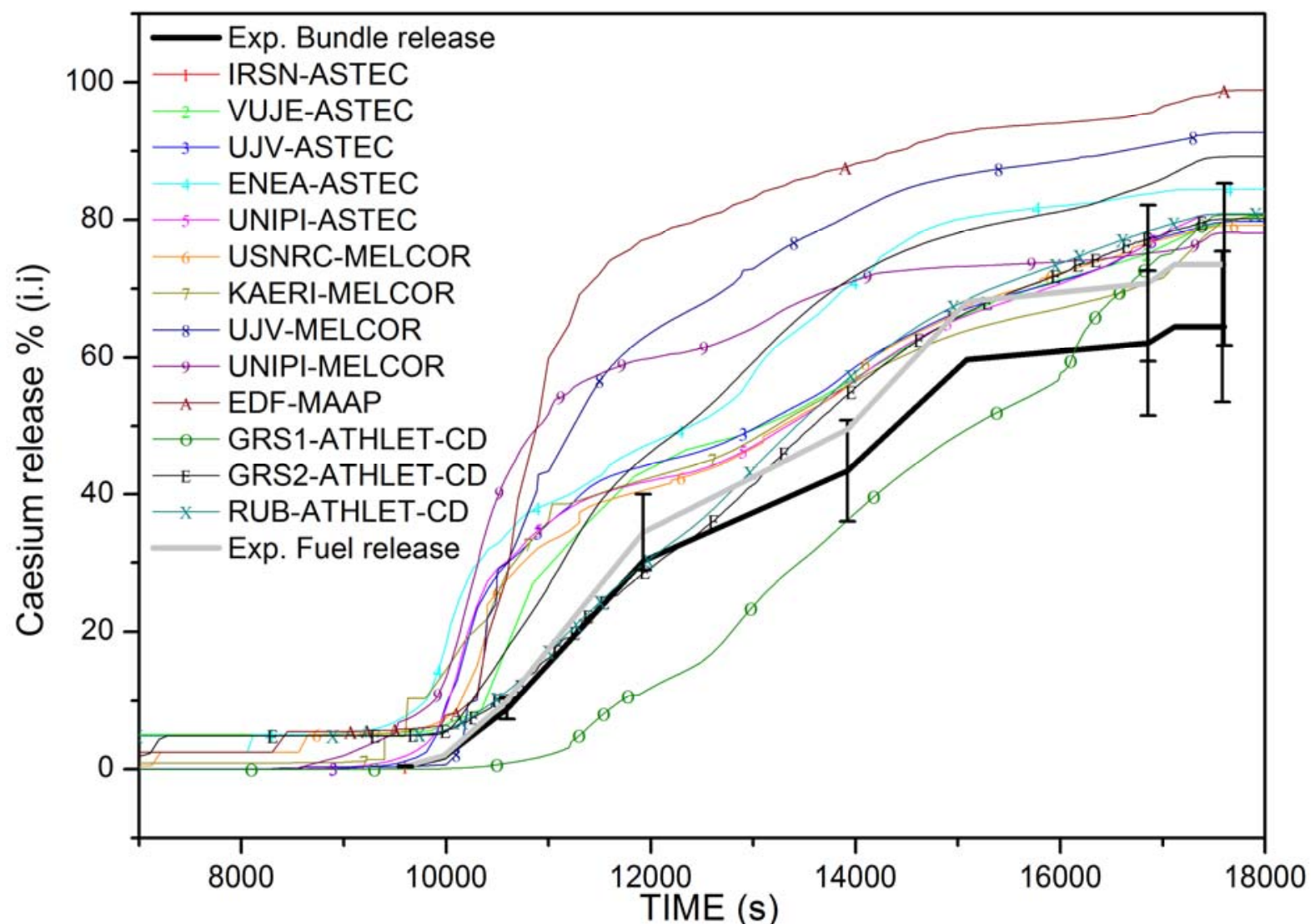

Figure 11: Caesium release from the fuel and bundle 


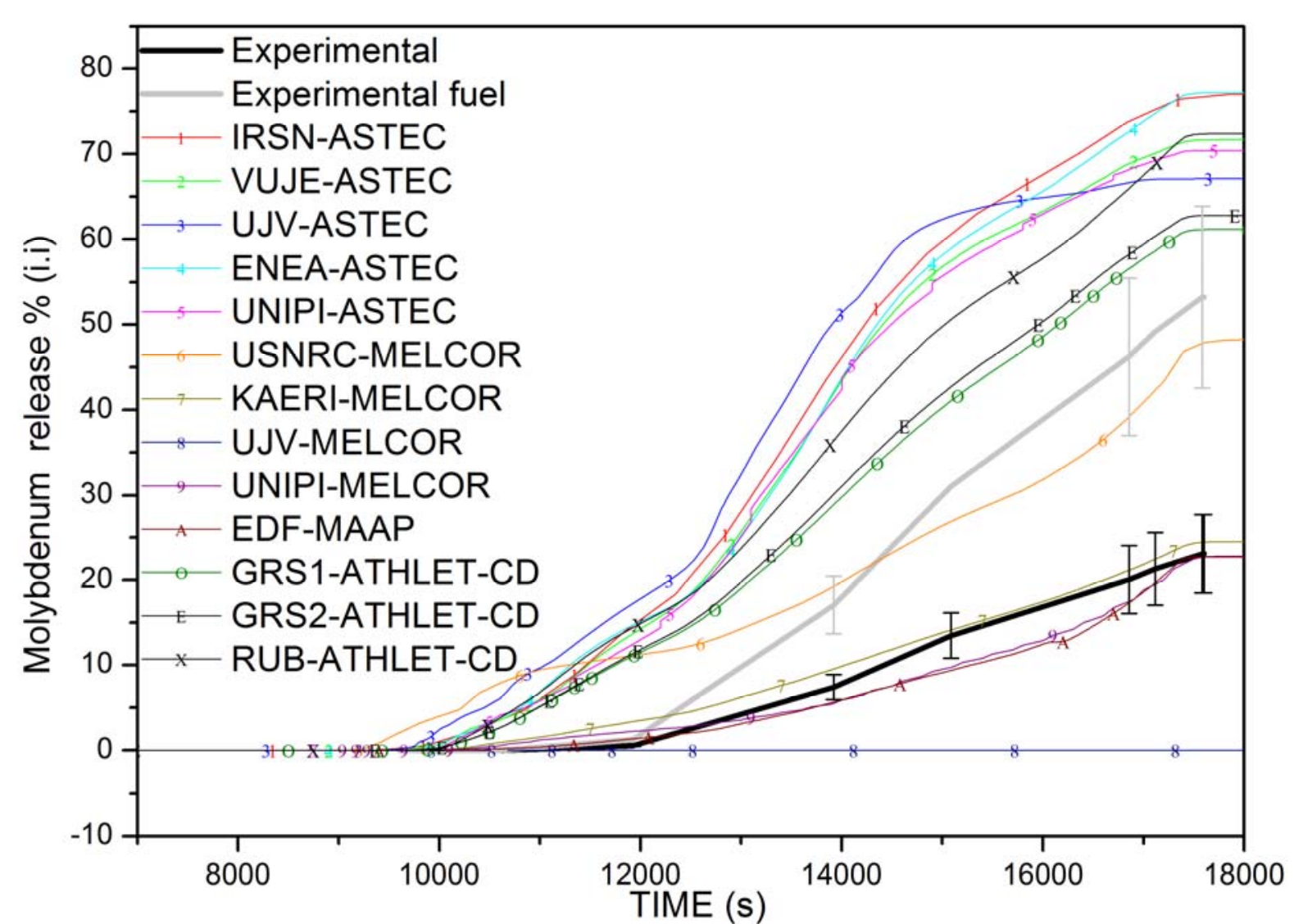

Figure 12: Molybdenum release from the fuel and bundle
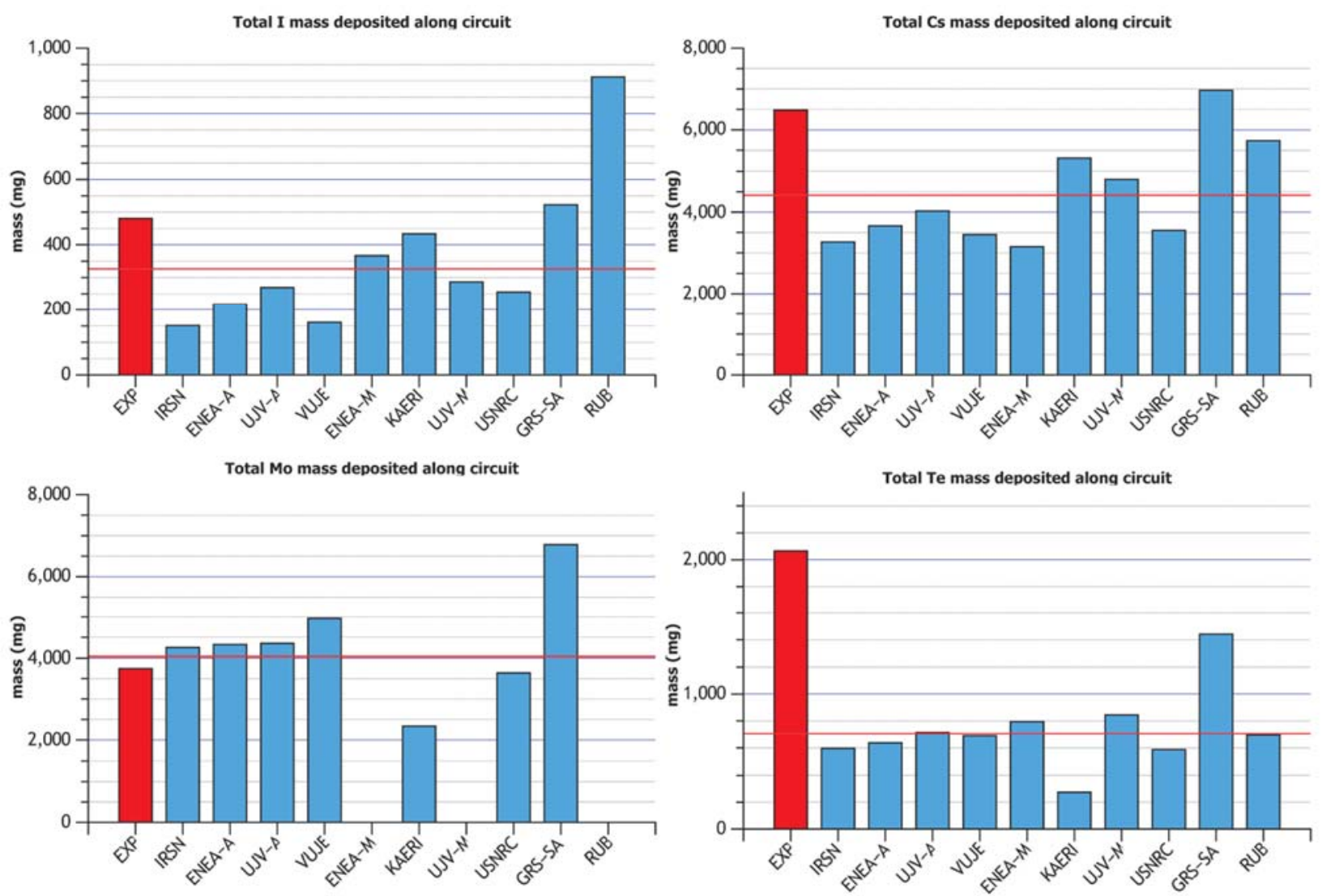

Figure 13: Overall mass retention of the fission products I, Cs, Te, Mo in the circuit 


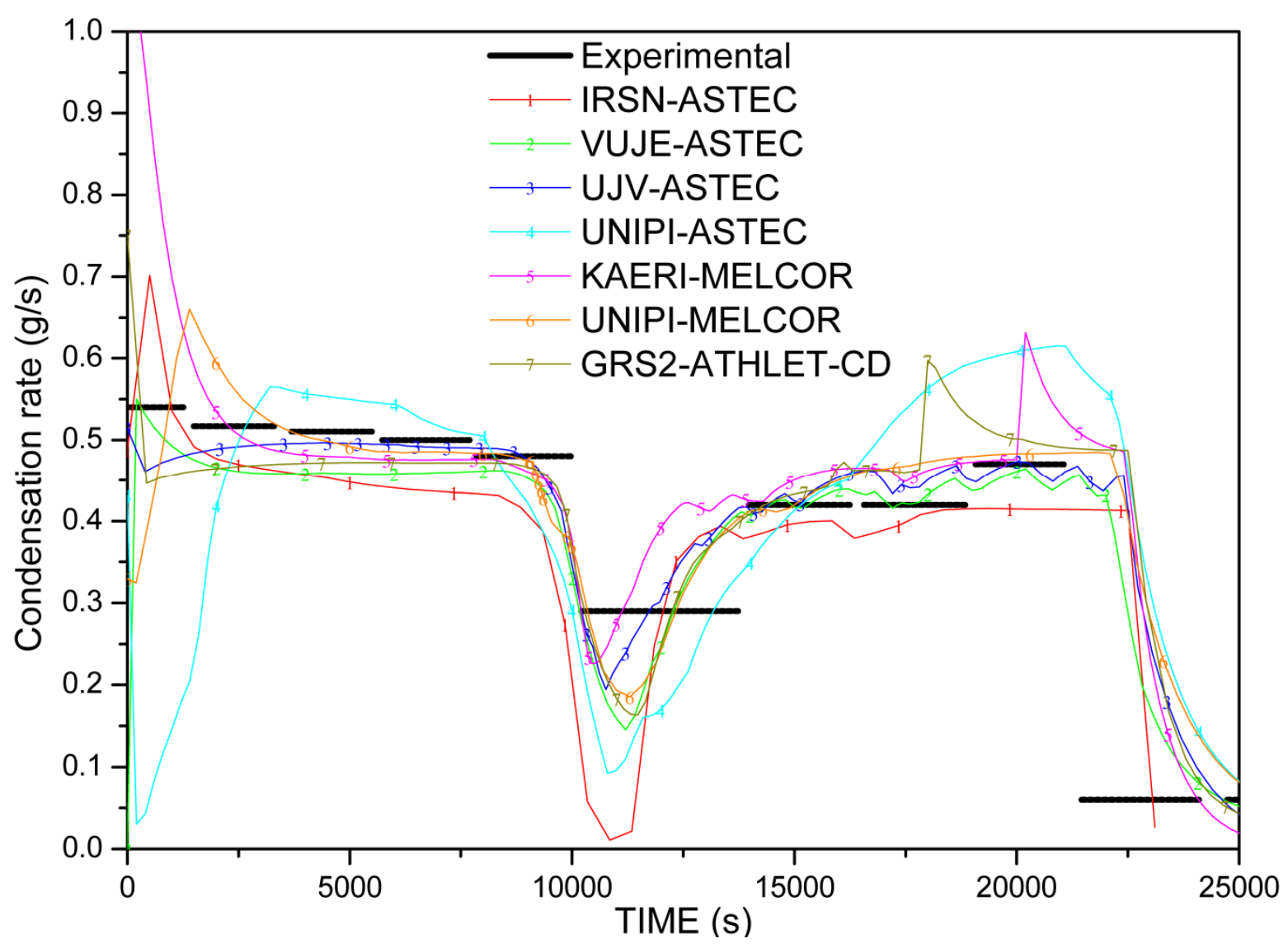

Figure 14: Containment condensation rate

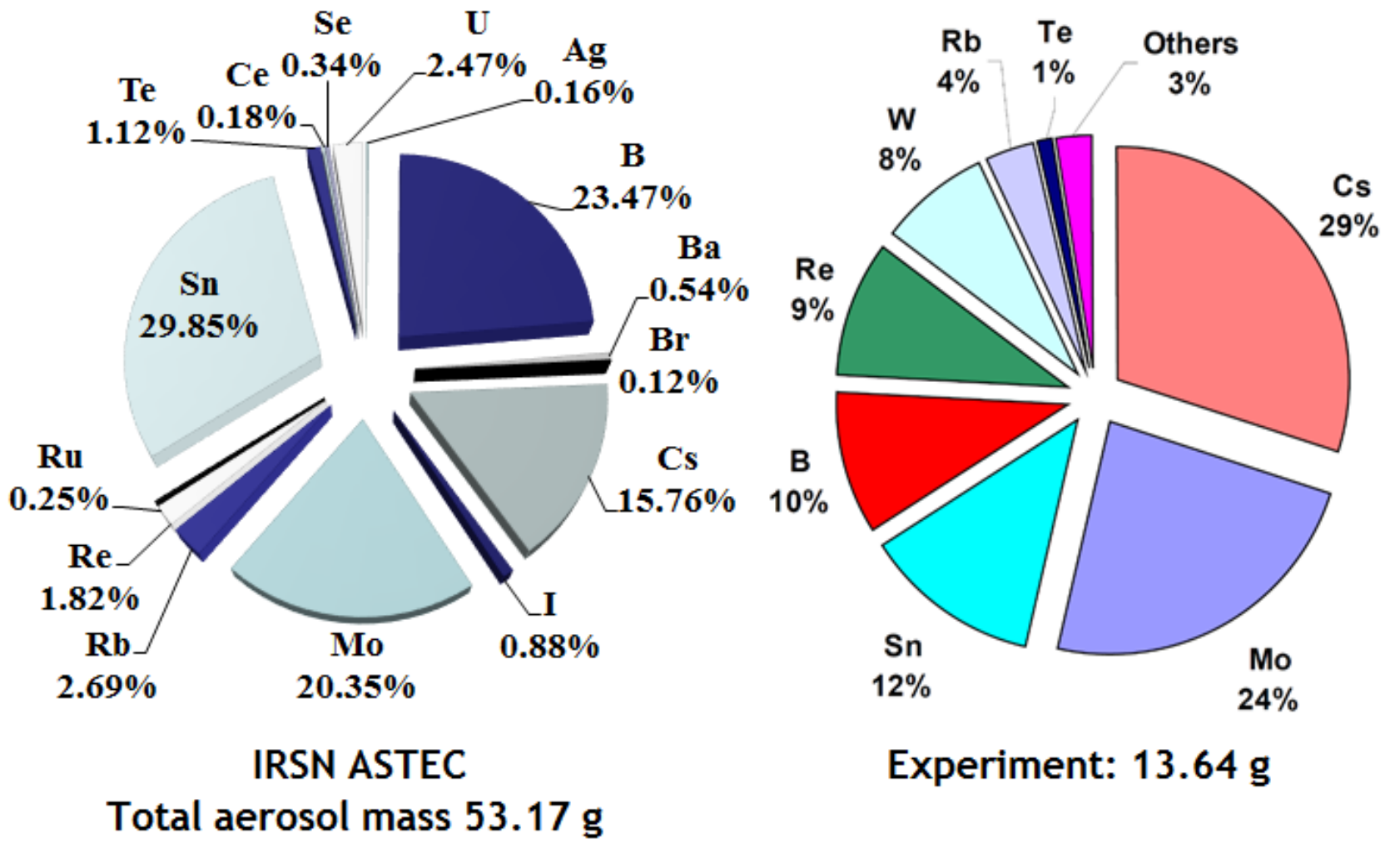

Figure 15: Aerosol speciation and mass entering the containment 


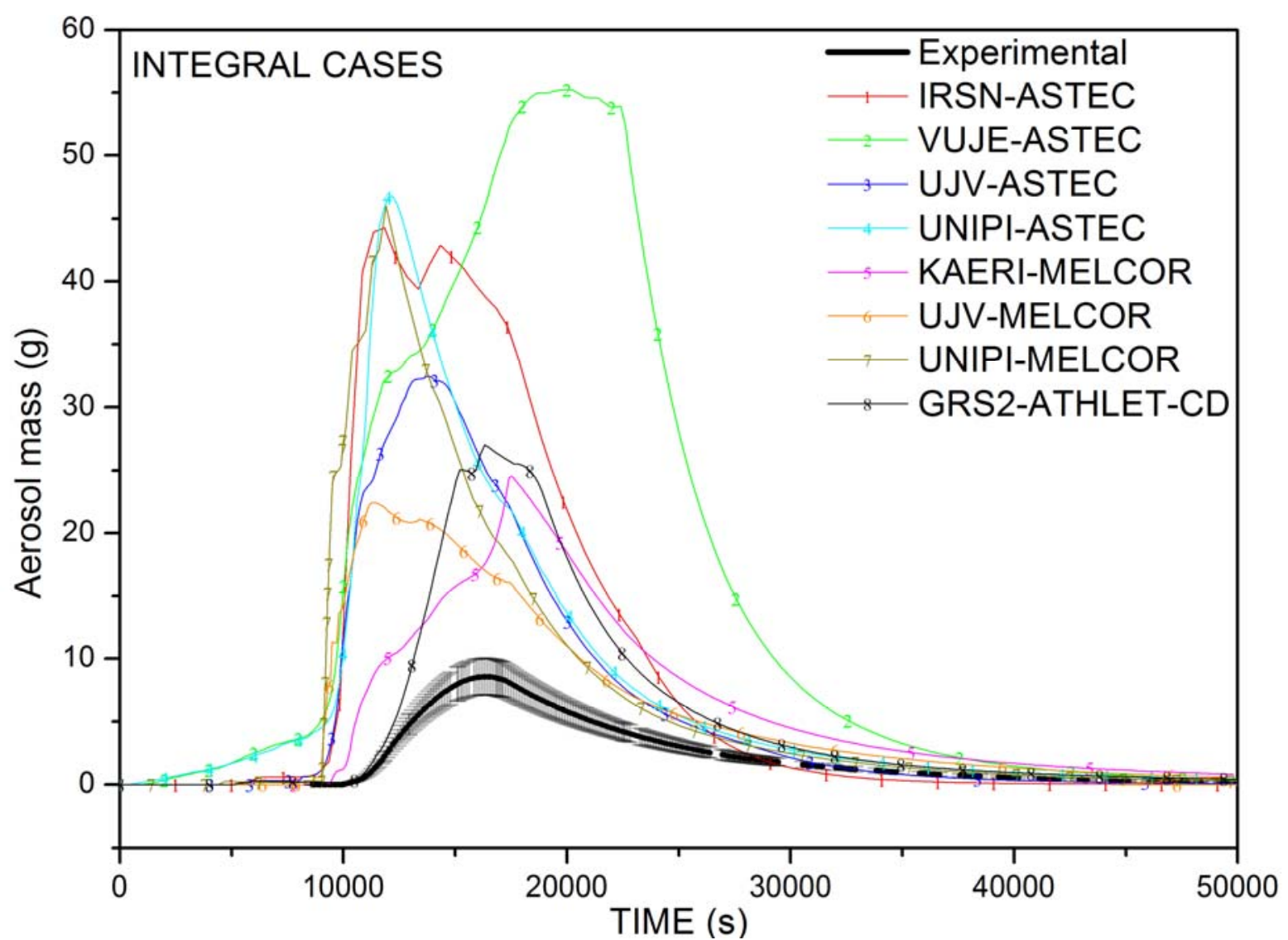

Figure 16: Total aerosol airborne mass integral cases 


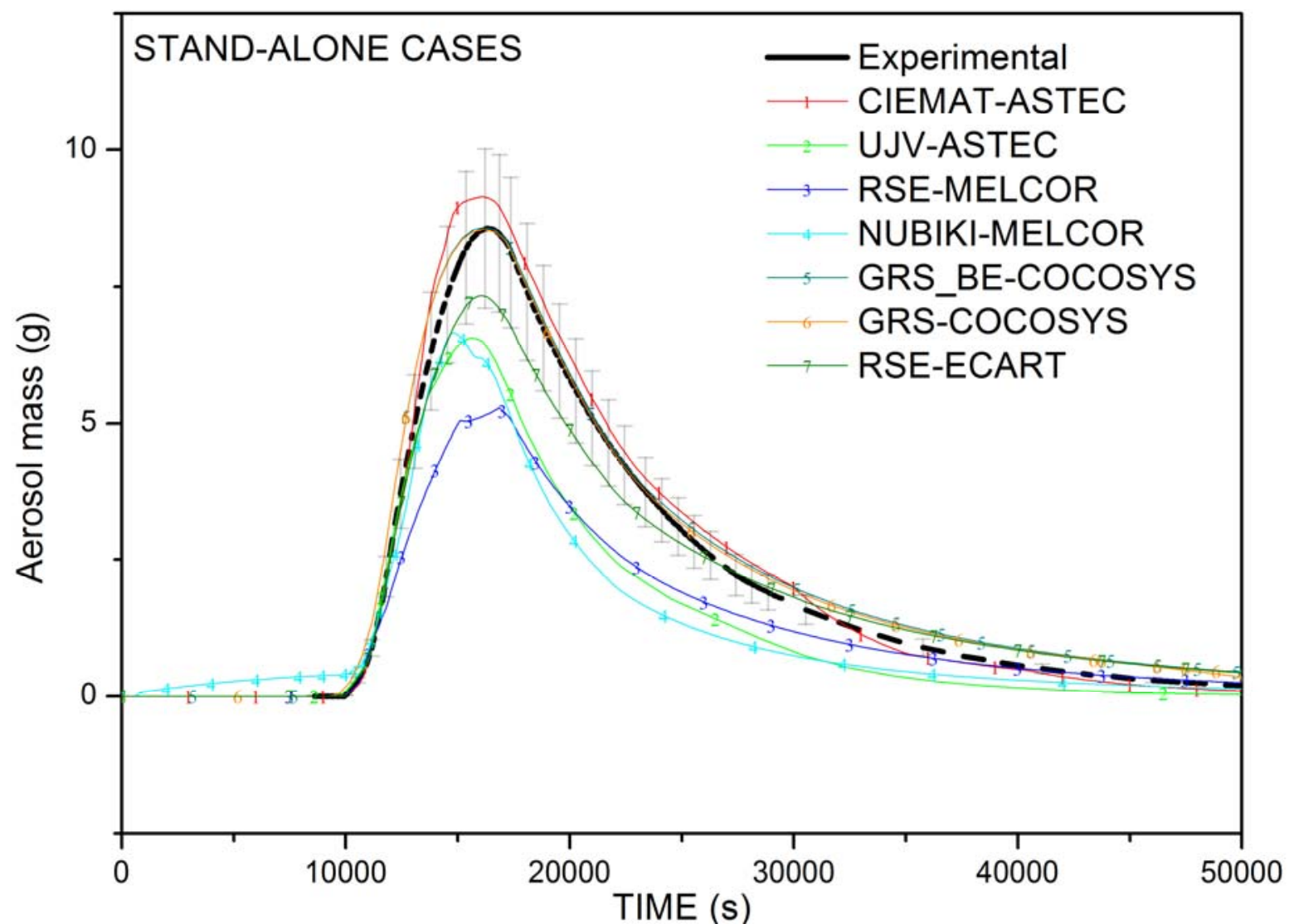

Figure 17: Total aerosol airborne mass stand-alone cases

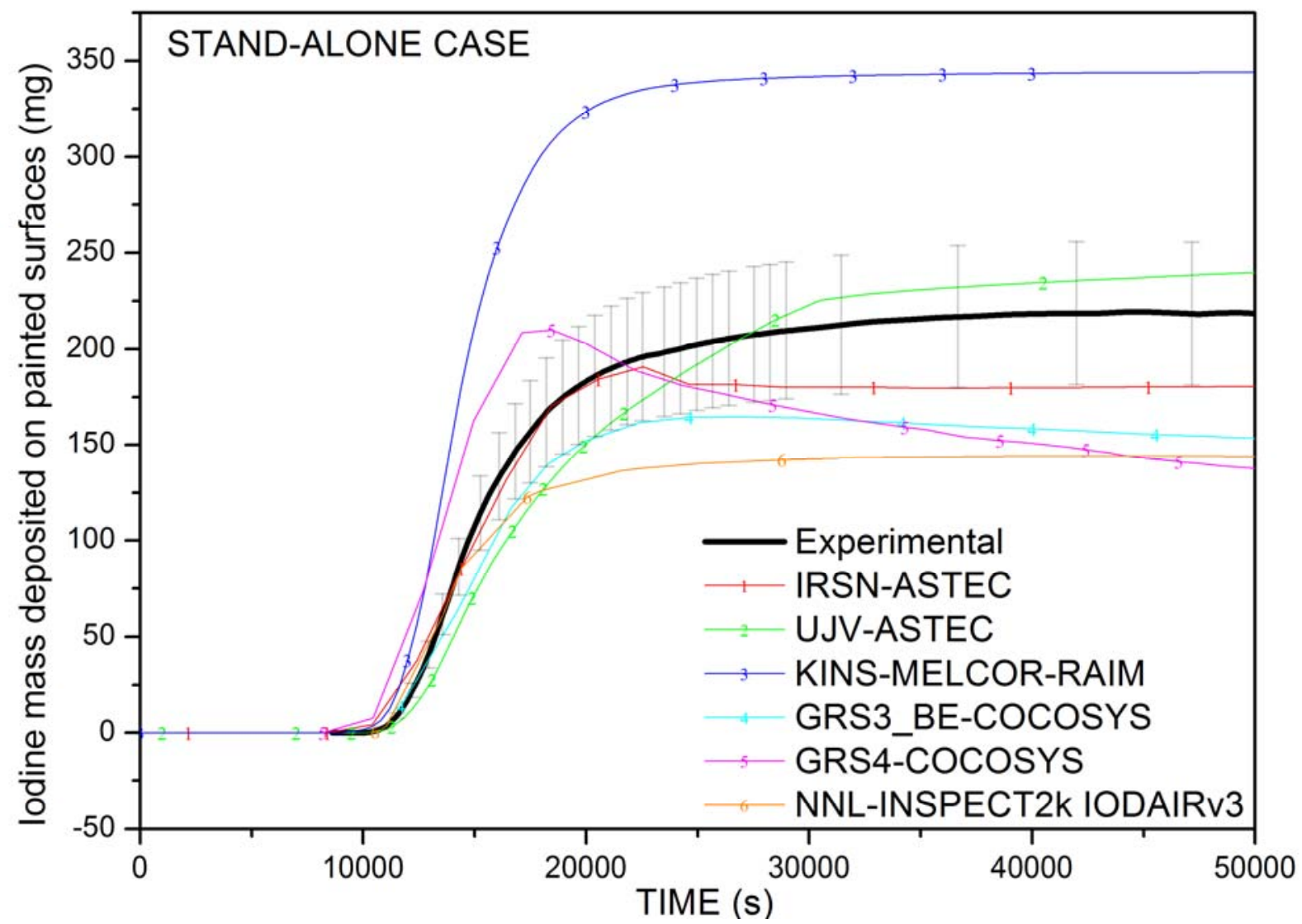

Figure 18: Iodine mass deposited on painted surfaces 


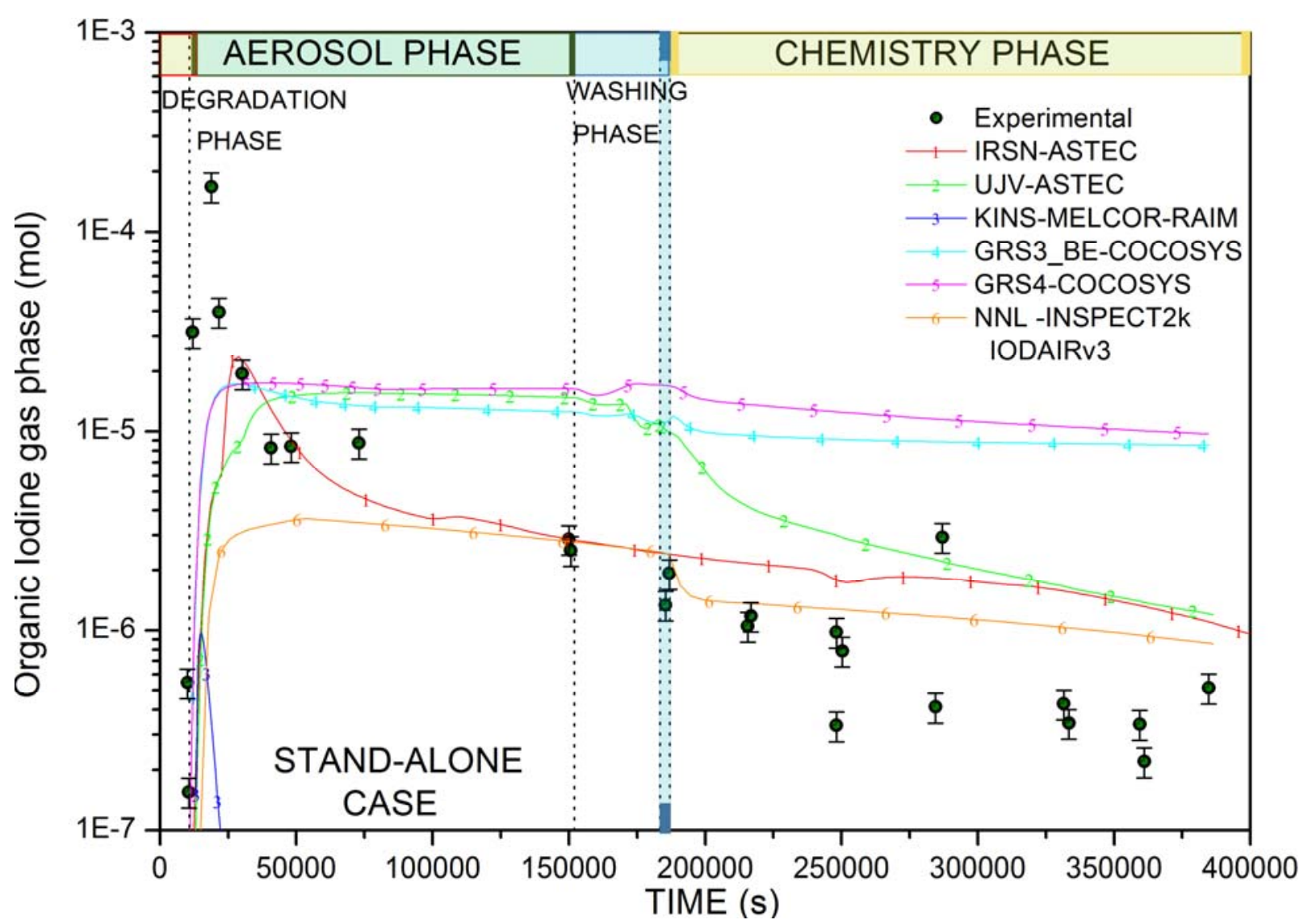

Figure 19: Organic iodine mass in containment atmosphere gas phase

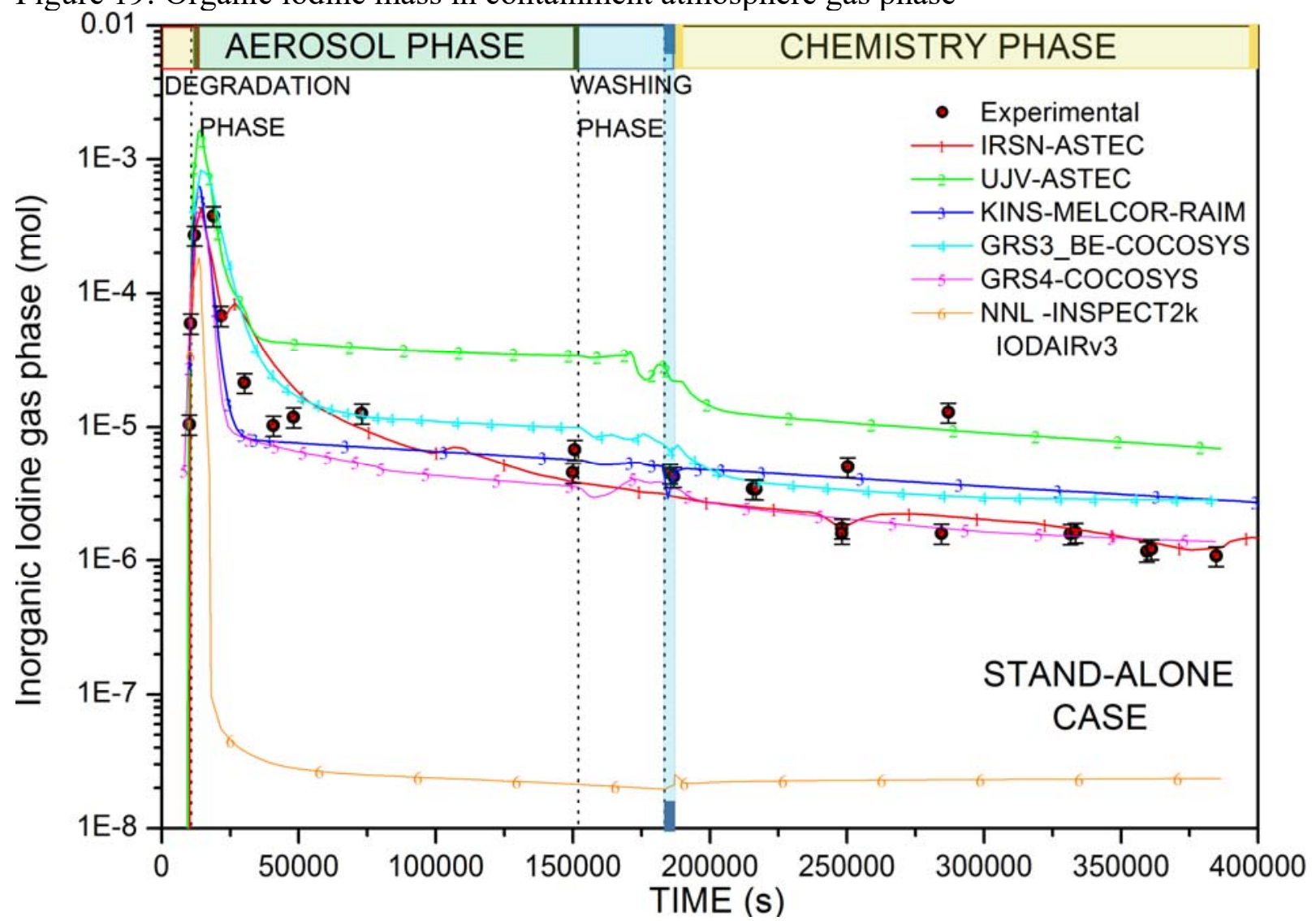

Figure 20: Inorganic iodine mass in containment atmosphere gas phase 